\title{
Identification, expression, and phylogenetic analyses of terpenoid biosynthesis-related genes in secondary xylem of loblolly pine (Pinus taeda L.) based on transcriptome analyses.
}

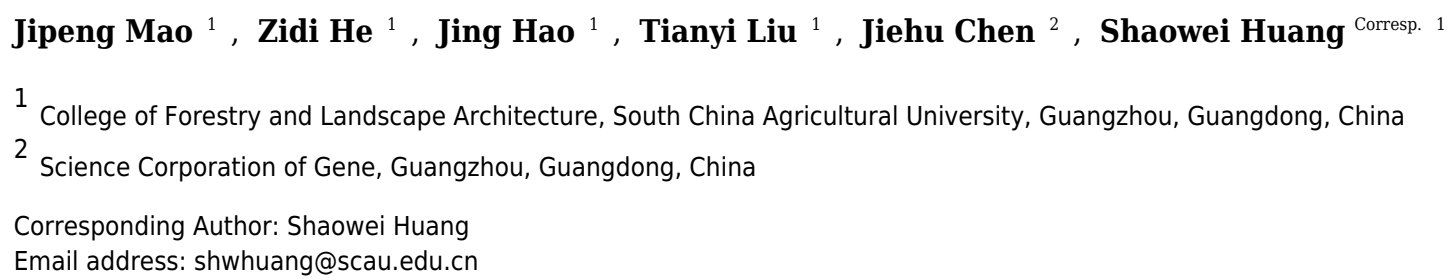

Loblolly pine (Pinus taeda L.) is one of the most important species for oleoresin (a mixture of terpenoids) in South China. The high oleoresin content of loblolly pine is associated with resistance to bark beetles and other economic benefits. In this study, we conducted transcriptome analyses of loblolly pine secondary xylem to gain insight into the genes involved in terpenoid biosynthesis. A total of 372 unigenes were identified as being critical for oleoresin production, including genes for ATP-binding cassette (ABC) transporters, the cytochrome P450 (CYP) protein family, and terpenoid backbone biosynthesis enzymes. Six key genes involved in terpenoid biosynthetic pathways were selected for multiple sequence alignment, conserved motif prediction, and phylogenetic and expression profile analyses. The protein sequences of all six genes exhibited a higher degree of sequence conservation, and upstream genes were relatively more conserved than downstream genes in terpenoid biosynthetic pathways. The N-terminal regions of these sequences were less conserved than the $\mathrm{C}$-terminal ends, as the $\mathrm{N}$-terminals were quite diverse in both length and composition. The phylogenetic analyses revealed that most genes originated from gene duplication after species divergence, and partial genes exhibited incomplete lineage sorting. In addition, the expression profile analyses showed that all six genes exhibited high expression levels during the high-oleoresin-yielding phase. 
3 Jipeng $\mathrm{Mao}^{1}$, Zidi He${ }^{1}$, Jing Hao ${ }^{1}$, Tianyi $\mathrm{Liu}^{1}$, Jiehu Chen², Shaowei Huang ${ }^{1}$

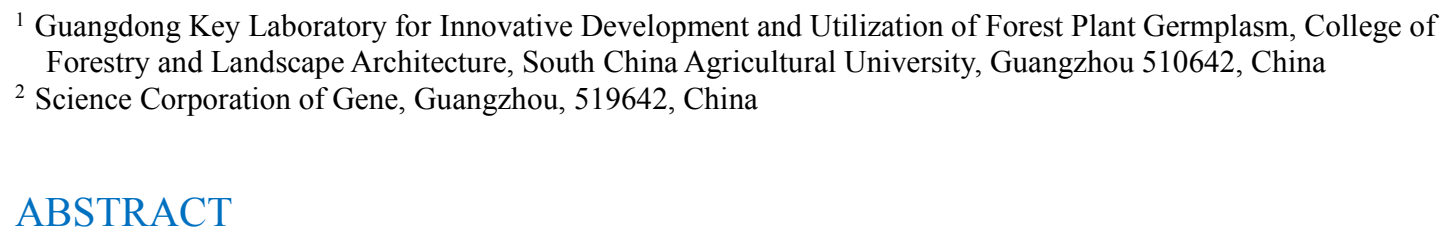

${ }^{1}$ Guangdong Key Laboratory for Innovative Development and Utilization of Forest Plant Germplasm, College of Forestry and Landscape Architecture, South China Agricultural University, Guangzhou 510642, China

${ }^{2}$ Science Corporation of Gene, Guangzhou, 519642, China

Loblolly pine (Pinus taeda L.) is one of the most important species for oleoresin (a mixture of terpenoids) in South China. The high oleoresin content of loblolly pine is associated with resistance to bark beetles and other economic benefits. In this study, we conducted transcriptome analyses of loblolly pine secondary xylem to gain insight into the genes involved in terpenoid biosynthesis. A total of 372 unigenes were identified as being critical for oleoresin production, including genes for ATP-binding cassette (ABC) transporters, the cytochrome P450 (CYP) protein family, and terpenoid backbone biosynthesis enzymes. Six key genes involved in terpenoid biosynthetic pathways were selected for multiple sequence alignment, conserved motif prediction, and phylogenetic and expression profile analyses. The protein sequences of all six genes exhibited a higher degree of sequence conservation, and upstream genes were relatively more conserved than downstream genes in terpenoid biosynthetic pathways. The $\mathrm{N}$-terminal regions of these sequences were less conserved than the $\mathrm{C}$-terminal ends, as the $\mathrm{N}$-terminals were quite diverse in both length and composition. The phylogenetic analyses revealed that most genes originated from gene duplication after species divergence, and partial genes exhibited incomplete lineage sorting. In addition, the expression profile analyses showed that all six genes exhibited high expression levels during the high-oleoresin-yielding phase.

Keywords: Loblolly pine (Pinus taeda L.), Transcriptome analyses, Terpenoid biosynthesis, 


\section{INTRODUCTION}

28 The loblolly pine's amenability to plantation management, high wood yields, and fast growth

29 make it one of the most economically important forest species in the world (Lu et al., 2017).

30 Loblolly pine is also a potential renewable feedstock for alternative energy and fuel, as well as an

31 important source for oleoresin (Olatunde et al., 2017). Oleoresin is a viscous mixture of terpenoids stored in resin canals or blisters in the stems of conifers (Trapp and Croteau, 2001).

Resin canals are a characteristic structure of Pinus, and as transport channels for resin, they are closely related to pine resistance to pests. The resin canals distributed in secondary vascular structures can be divided into transverse and vertical resin canals. In the secondary xylem in particular, the transverse and vertical resin canals form a two-dimensional network structure; this two-dimensional resin canal structure allows the pine plant to effectively secrete resin at any point of invasion when subjected to biotic stresses (Chen et al., 2002). In conifers, the yield of oleoresin is a quantitative trait under moderate genetic control. Meanwhile, the production of oleoresin is correlated with growth traits and meteorological factors (An and Ding, 2010).

41 Oleoresin plays a key role in the defense system of coniferous trees, is widely used for industrial chemicals, and can be explored as a precursor for biofuels (Yamada et al., 2015). However, partial volatile terpenoids are also inducible upon insect herbivory, oviposition, or fungal inoculation. These relationships are ancient and complex (Scott et al., 2004).

Terpenoids, an important secondary metabolite in plants, are derived from the five-carbon biosynthetic building blocks isopentenyl diphosphate (IPP) and its isomer, dimethylallyl diphosphate (DMAPP). IPP and DMAPP are formed in two independent pathways: the mevalonate (MVA) and 2-C-methylerythritol-4-phosphate (MEP) pathways, localized in the cytosol/endoplasmic reticulum and plastids, respectively (Eisenreich et al., 1998; Rohmer et al.,

50 1999). Condensation of IPP and DMAPP is catalyzed by prenyltransferases and yields three 51 central intermediates of the isoprenoid pathway: geranyl diphosphate (GPP), farnesyl 52 diphosphate (FPP), and geranylgeranyl diphosphate (GGPP). The numerous structurally diverse 
53 plant terpenoids are then formed from these prenyl diphosphate precursors by terpene synthases

54 (Miller et al., 2001). During the biosynthesis of terpenoids, there are many other terpenoid

55 backbone biosynthesis key enzymes involved, such as 1-deoxy-D-xylulose 5-phosphate synthase (DXS) and 1-deoxy-D-xylulose 5-phosphate reductoisomerase (DXR) are the first two step enzymes of MEP pathway and play a critical role in the overall regulation of the pathway (Lois et al., 2000; Cordoba et al., 2009). 3-hydroxy-3-methylglutaryl-CoA reductase (HMGR) is a key enzyme of the MVA pathway (Rodríguez-Concepcion et al., 2015). Isopentenyl diphosphate isomerase (IPPI) acts on isomerization between IPP and DMAPP which are the precursors to all isoprenoid compounds (Zulak et al., 2010). The geranyl diphosphate synthase (GPS), geranylgeranyl diphosphate synthase (GGPS) and farnesyl diphosphate synthase (FPS) are the precursors to monoterpenes, diterpenes and sesquiterpenes of conifer oleoresin, respectively (Zulak et al., 2010). Furthermore, previous studies have confirmed that ABC transporters (Jasinski et al., 2001), several cytochrome P450 family proteins (Banerjee and Hamberger, 2018), aldehyde/alcohol dehydrogenases (ALDH/ADH) (Teoh et al., 2009; Polichuk et al., 2010), pathogenesis-related proteins (Dafoe et al., 2009), non-specific lipid-transfer proteins (Liu et al., 2015), and ethylene responsive transcriptionfactors (ERFs) (Xu et al., 2007) are also crucial for terpenoid biosynthesis.

With the decreasing cost of sequencing, transcriptome analyses based on RNA-Seq technology has been widely used in many plant species to identify target genes or acquire other useful genomic information. For example, transcriptome analyses of Pinus massoniana (Liu et al., 2015), Lindera glauca (Niu et al., 2015), Thapsia laciniata (Drew et al., 2013), Isodon rubescens (Su et al., 2016), and Calotropis procera (Pandey et al., 2016) were conducted to identify candidate genes related to terpenoid biosynthesis. The loblolly pine (Pinus taeda) genome has been sequenced (Zimin et al., 2014) and contains 20.15 billion bases, approximately seven times that of the human genome. It is the largest sequenced genome and the most complete published conifer genome sequence, yet few studies have reported transcriptome analyses of 
79 Pinus taeda secondary xylem. We performed transcriptome analyses of loblolly pine secondary

80

81

82

83

84

85

86

xylem for two reasons: first, the secondary xylem is the main tissue involved in the secretion of terpenoids; second, the collection of resin in South China is based on the bark streak method (Fig. 1a) instead of using the pine needles as the material for alcohol extraction. We conducted an integrated analyses of terpenoid biosynthesis encompassing the identification of related genes, the phylogenetic relationships among representative genes in other characterized species, the expression profiles of different oleoresin-yielding stages, and the prediction of conserved motifs. We provide an extensive perspective of regulatory factors involved in terpenoid biosynthesis in the loblolly pine, as well as a portfolio of candidate genes for future study.

\section{MATERIALS AND METHODS}

\section{Plant materials}

Because of the content of oleoresin was different between individuals, and influenced by the meteorological factors. In this study, three 15-year-old loblolly pine trees from the Yingde Research Institute of Forestry in Guangdong Province, China, were used to RNA sequencing to find out the genes involved in terpenoid biosynthetic pathway. They shared no lineage relationships. During the high-oleoresin-yield stage (August) (An and Ding, 2010), secondary xylem tissue samples $\sim 1 \mathrm{~mm}$ in thickness were collected from the trees after removing the bark at breast height using a firewood chopper and removing the phloem and cambium using a $75 \%$ alcohol-treated grafting knife (Fig. 1b). The samples were immediately immersed in liquid nitrogen and then stored at $-80^{\circ} \mathrm{C}$ until RNA extraction.

\section{RNA isolation}

Total RNA was extracted from each sample following a protocol modified from Chang et al. (1993). Briefly, secondary xylem tissues $(\sim 150 \mathrm{mg})$ were ground into powder under liquid nitrogen, then immediately transferred to $1.5 \mathrm{~mL}$ RNase-free centrifuge tubes. Next, $1 \mathrm{~mL} \mathrm{CTAB}$ 
105 extraction buffer (100 mM Tris-HCl, pH 8; 25 mM EDTA, pH 8; $2 \mathrm{M} \mathrm{NaCl;2 \%} \mathrm{CTAB;2 \%}$

$106 \mathrm{PVP}$ ) and $20 \mu \mathrm{L} \beta$-mercaptoethanol were added to the tubes, mixed by vortexing for $2 \mathrm{~min}$, and 107 incubated at $65^{\circ} \mathrm{C}$ for $20 \mathrm{~min}$. Following incubation, samples were centrifuged for $10 \mathrm{~min}$ at $10812,000 \mathrm{rpm}$ at $4^{\circ} \mathrm{C}$. The supernatant was collected into a new $1.5 \mathrm{~mL}$ centrifuge tube and an 109 equal volume of chloroform/isoamyl alcohol (24:1) was added, mixed by vortexing for 2 min, 110 and centrifuged for $5 \mathrm{~min}$ at $12,000 \mathrm{rpm}$ at $4^{\circ} \mathrm{C}$. After an additional chloroform/isoamyl alcohol 111 extraction, the supernatant was collected into a new tube and a 1/4-volume of $10 \mathrm{M} \mathrm{LiCl}$ was 112 added, mixed, and incubated at $4^{\circ} \mathrm{C}$ for $6 \mathrm{~h}$. After precipitation for $6 \mathrm{~h}$, the sample was 113 centrifuged for $10 \mathrm{~min}$ at $12,000 \mathrm{rpm}$ at $4^{\circ} \mathrm{C}$, and the supernatant was discarded. The sediment 114 was washed twice with $500 \mu \mathrm{L} 75 \% \mathrm{EtOH}$ and $500 \mu \mathrm{L}$ anhydrous alcohol precooled at $-20^{\circ} \mathrm{C}$, 115 respectively. The sample was dried for $5 \mathrm{~min}$, then resuspended in $50 \mu \mathrm{L}$ DEPC-treated water. 116 Total RNA concentration and integrity were determined, and high-quality RNAs were used for 117 cDNA library construction.

cDNA library construction, sequencing, and sequence assembly cDNA libraries were constructed following the protocol described by Foucart et al. (2006). Libraries were sequenced with $2 \times 100$ paired-end reads using the Illumina HiSeq 4000 platform at Science Corporation of Gene (Guangzhou, China). The Trinity method (Haas et al., 2013) was used to assemble the high-quality reads into unigenes. RNA sequence data were deposited in the National Center for Biotechnology Information (NCBI) Sequence Read Archive (SRA) under the study accession number PRJNA482703.

128 To identify genes related to terpenoid biosynthesis, all unisequences were queried against five 129 public protein databases (UniProt, Nr, KEGG, KOG, and GO) with an E-value threshold $<10^{-5}$ 130 to detect unigenes homologous to previously identified relevant genes. The Blast2GO software 
131 (version 4.1.5) with the default parameters (Conesa et al., 2005) was used to obtain GO

132 annotation of unigenes. WEGO (Ye et al., 2006) was used to perform GO functional 133 categorization for all unisequences. KEGG pathway analyses were performed using BLASTx 134 queries against the KEGG database (http://www.genome.jp/kegg/).

\section{Multiple sequence alignment analyses and conserved motif prediction}

137 Multiple sequence alignments were performed using ClustalW (https://www.genome. $138 \mathrm{jp} /$ tools-bin/clustalw) and images were displayed using a multi-sequence comparison display tool 139 (http://www.bio-soft.net/sms/multi_align.html). The conserved motif predictions were performed 140 using the Multiple Em for Motif Elicitation (MEME) tool (http://meme.sdsc.edu/meme/cgi$141 \mathrm{bin} / \mathrm{meme.cgi}$ ) (Bailey and Elkan, 1994) with the default parameters.

\section{Phylogenetic analyses}

144 Phylogenetic analyses were performed based on the protein sequences of six completely 145 assembled representative genes (if more than one homologous unigene was fully assembled, the 146 unigene with the largest sequence length was used for subsequent analyses); alignments were 147 performed using the MUSCLE (v3.8.30) program. Phylogenetic trees were constructed using two 148 methods: maximum likelihood (ML) in RAxML (8.1.5) with 1000 bootstrap replicates in view of 149 the best-scoring model, and Bayesian inference (BI) in MrBayes (3.2.6) with 10,000,000 150 generations. The best models were selected using ProtTest3, and the BI tree was reliable with a 151 standard deviation of split frequencies $<0.01$. The phylogenetic trees were drawn with MEGA 1527.0 (Kumar et al., 2016).

154 Quantitative reverse transcription PCR (qRT-PCR) analyses

155 To investigate the expression profiles of six representative genes involved in the biosynthesis of 156 terpenoids, total RNAs from three different oleoresin-yielding stages were extracted as described 
157 for the cDNA library preparation. Samples from two low-oleoresin-yield phases were collected

158 in April and October; the high-oleoresin-yield RNA samples (August) were the same samples

159 used for cDNA library construction. Reverse transcription was performed using a PrimeScript ${ }^{\mathrm{TM}}$

160 RT reagent kit with a gDNA Eraser (Code No: RR047A, TaKaRa, Dalian, China) following the

161 manufacturer's instructions. The primers for the six candidate gene sequences were designed

162 using Primer Premier 5.0, and Actin (F: gagcaaagagatcactgcacttg; R: ctcatattcggtcttggcaatcc) was

163 selected as an internal control (primers are listed in Supplementary Table 1). The qRT-PCR

164 analyses were performed using a LightCycler 480 System (Roche, Basel, Switzerland) and a TB

165 Green Premix Ex Taq II kit (Code No: RR820A, TaKaRa). A $20 \mu \mathrm{L}$ reaction containing $2 \mu \mathrm{L}$

166 synthesized cDNA, $10 \mu \mathrm{L} 2 \times \mathrm{TB}$ Green Premix Ex Taq mix, $0.8 \mu \mathrm{L} 10 \mu \mathrm{M}$ forward primer, 0.8

$167 \mu \mathrm{L} 10 \mu \mathrm{M}$ reverse primer, and $6.410 \mu \mathrm{L}$ sterile distilled water was amplified using the following

168 procedure: one cycle of $95^{\circ} \mathrm{C}$ for $30 \mathrm{~s}$, followed by 40 cycles of $95^{\circ} \mathrm{C}$ for $5 \mathrm{~s}, 55^{\circ} \mathrm{C}$ for $30 \mathrm{~s}$, and

$16972^{\circ} \mathrm{C}$ for $30 \mathrm{~s}$. Three biological replicates (consistent with the samples used for library 170 construction) of each oleoresin-yielding stage were performed, and each PCR reaction included

171 three technical replicates. The relative expression levels of candidate genes were calculated using 172 the $2^{-\Delta \Delta C t}$ method (Livak et al., 2001).

174 RESULTS

RNA-Seq and transcriptome assembly

176 To obtaine a summarization of the loblolly pine transcriptome in secondary xylem tissues during 177 the high-oleoresin-yielding phase (August), total RNAs extracted from three samples were used 178 for RNA-Seq on an Illumina HiSeq 4000 platform. After quality appraisal and low-quality data 179 screening, 29,559,842 high-quality reads were generated and assembled into 115,399 transcripts 180 with a mean length of 688 bp and an N50 of 1255 bp. Among these transcripts, 20,757 (17.98\%) 181 were $>1 \mathrm{~kb}$. Finally, we obtained 74,402 unigenes with a mean length of 1459 bp (Fig. 2). 


\section{Functional annotation and classification}

184 A total of 31,586 unigenes $(42.45 \%)$ were annotated with a threshold E-value $<10^{-5}$ after

185

186

187

188

189

190

191

192

193

194

195

196

197

198

199

200

201

202

203

204

205

206

207

BLASTx searches against the five protein databases (Supplementary Table 2). Among them, 31,370 (42.16\%), 30,395 (40.85\%), 27,942 (37.56\%), 24,871 (33.43\%), and 22,433 (30.15\%)

unigenes were annotated by the UniProt, Nr, KEGG, KOG, and GO databases, respectively (Table 1, Fig. 3). Based on the $\mathrm{Nr}$ database, 5,807 (18.38\%) unigenes exhibited significant homology with sequences from Picea sitchensis, and 1,877 (6.10\%) and 1,305 (4.13\%) unigenes shared high similarity with sequences from Amborella trichopoda and Nelumbo nucifera, respectively (Supplementary Fig. 1).

GO assignments based on sequence homology were used to classify the functions of annotated unigenes. In all, 22,433 unigenes were distributed into three main GO terms ("biological process", "cellular component" and "molecular function") and 44 secondary-class GO terms (Fig. 4). The two largest GO functional groups of the "molecular function" term were "catalytic activity" and "binding". The most represented "cellular component" categories were "membrane part" and "cell part". The most represented "biological process" categories were "metabolic process", "single organism process" and "cellular process". Several important secondary-class GO terms related to terpenoid metabolism were also represented at lower numbers, such as "response to stimulus", "transporter activity" and "biological regulation" (Fig. 4). In general, the GO analyses revealed that most unigenes were responsible for basic biological process regulation and metabolism.

To further enhance the reliability of the transcriptome annotation process, the KOG database was used to classify the functional groups of all annotated unigenes. In our study, 18,786 matched unigenes were classified into 25 groups (Fig. 5). Among these groups, the largest number of unigenes $(7419,39.49 \%)$ were classified as "general function prediction only". In addition, some groups related to the metabolism of terpenoids such as: "lipid transport and 
208 metabolism" (549 unigenes), "secondary metabolites biosynthesis, transport, and catabolism"

209 (674 unigenes), and "defense mechanisms" (148 unigenes) were also highly represented.

210 However, only 50, 38, and 3 unigenes matched "nuclear structure", "extracellular structure" and

211 "motility", respectively. Functional classification of unigenes focusing on biochemical pathways

212 was conducted using the KEGG annotation system. In our study, 10,266 unigenes were assigned

213 to 35 pathways (Fig. 6). Most plant biochemical pathways were represented, including

214 "metabolism", "organismal systems", "genetic information processing", "cellular processes" and

215 "environmental information processing". The most represented pathway was "global and

216 overview maps" $(2031,19.78 \%)$. In addition, a total of 123 unigenes were involved in the

217 terpenoid biosynthetic pathway (Supplementary Figs. 2-4; Supplementary Table 3).

219 Identification of oleoresin biosynthesis-related genes

220 After combining the functional annotation with previous research results, a total of 249 unigenes

221 (not including the 123 unigenes involved in the terpenoid biosynthetic pathway) were identified

222 as crucial for oleoresin biosynthesis. Among these, 105 ABC transporter genes were identified

223 and mainly divided into seven subfamilies (A, B, C, D, F, G, and I) (Supplementary Table 4). In

224 all, 67 genes were annotated as cytochrome P450 family proteins, including many known

225 subfamilies related to terpenoid biosynthesis, such as cytochrome P450 family members CYP720,

226 CYP71, CYP701, CYP51, CYP76, CYP704, and CYP716 (Supplementary Table 5). In addition,

227 there were 20 alcohol dehydrogenase genes, 10 aldehyde dehydrogenase genes, 17 pathogenesis-

228 related protein (PR5 and PR10) genes, 13 ethylene-responsive transcription factor genes, 13

229 terpenoid synthase genes (Table 2), 3 non-specific lipid-transfer protein genes, and 1 230 phosphomethylpyrimidine synthase gene (Supplementary Table 6).

\section{Multiple sequence alignment and conserved motif prediction}

233 BLASTP searches against the $\mathrm{Nr}$ database for comparative sequence analyses of DXR, DXS, 
234 HMGR, IPPI, GGPS, and FPS proteins were conducted separately. A total of 14 additional

235 representative plant species containing the six protein sequences were retrieved (if multiple

236 protein sequences were retrieved for a species, the one with the highest BLASTP score was

237 selected for analyses) (Table 3). Among them were three gymnosperm species, four

238 monocotyledons, and seven dicotyledons. Multiple sequence alignment analyses revealed that

239 the FPS (Supplementary Fig. 5e) and GGPS (Supplementary Fig. 5f) sequences were less

240 conserved compared to the other four protein sequences, and the C-terminal regions of the six

241 protein sequences were more conserved than the $\mathrm{N}$-terminal ends. The $\mathrm{N}$-terminals of these

242 protein sequences were quite diverse in both length and composition (Supplementary Fig. 5).

243 In our study, the MEME motif search tool was used to discover the motifs of the 15 DXR,

244 DXS, HMGR, IPPI, GGPS, and FPS protein sequences, respectively. The results identified a

245 total of 10 motifs for each sequence (except the IPPI protein sequence, which had 9), named

246 motifs 1-10, separately (Fig. 7 and Supplementary Fig. 6). For the DXR protein sequences, six

247 identical instances of motif 3, and two identical instances of motifs 7, 8, and 9 were discovered

248 in different locations, respectively. All members contained motifs 2, 3a, 4, 3b, 5, 3c, 6, 7b, 8a, 9b,

249 and 10. Interestingly, the gymnosperm clade were all missing motifs 5, 3d, and 8b (except the

250 Picea sitchensis DXR sequence) (Fig. 7). Among the DXS protein sequences, motifs 5-10 were

251 more conserved than other motifs. Excepting the Taxus $\times$ media DXS sequence, the other 14

252 members contained motif 1 (Supplementary Fig. 6a). Analyses of conserved sequence motifs of

253 IPPI sequences revealed that motifs 4-8 were present in all members, and all but Taxus $\times$ media

254 contained motif 9. Motifs 1-3 were apparently less conserved as they were only detected in two,

255 six, and one members, respectively (Supplementary Fig. 6c). For the HMGR protein sequences,

25613 members contained motifs 1-10; the Elaeis guineensis HMGR sequence lost motif 10 and

257 Pinus taeda was missing motifs 6-10 (Supplementary Fig. 6b). For FPS protein sequences,

258 motifs 2-5 and 7-10 were present in all 15 members; only Oryza sativa japonica was missing

259 motif 1. Interestingly, four of the five members containing motif 6 came from the gymnosperm 
260 clade (Supplementary Fig. 6e). For GGPS protein sequences, only four motifs were present in all

26115 members, and only the three gymnosperm members contained motif 2 (Supplementary Fig. $2626 \mathrm{~d})$.

\section{Phylogenetic analyses}

265 To further investigate the evolutionary relationships of Pinus taeda terpenoid backbone 266 biosynthesis-related genes to those from other plants, six genes annotated as encoding terpenoid 267 backbone biosynthesis key enzymes were selected. Among them were three upstream genes $268(D X S, D X R$, and $H M G R)$, two downstream genes (FPS and GGPS), and one gene located at the 269 branching point (IPPI) (Fig. 8). For each gene, a phylogenetic tree was built using amino acid sequences from 15 species (Fig. 9). Phylogenetic analyses results showed that $D X S, D X R$, $H M G R$, and IPPI had the same unrooted topology. Amino acid sequences of $D X S, D X R, H M G R$, and IPPI genes from the 15 species were divided into three distinct monophyletic clades representing gymnosperms, dicotyledons, and monocotyledons (Fig. 9a,b,e,f). According to the branch lengths of each species in the phylogenetic tree, we speculate that the degree of evolution of these four genes roughly corresponds to the species divergence and traditional classification. However, FPS and GGPS exhibited anomalous unrooted molecular trees. The four FPS genes from the monocotyledons were divided into two branches, and the FPS gene of Ananas comosus had the longest branch length (Fig. 9d). In the phylogenetic tree of GGPS genes, the branch containing the two monocotyledons Oryza sativa japonica and Elaeis guineensis displayed a significantly higher degree of evolution than the other branches. In addition, the Zea mays (a typical monocotyledon) GGPS gene was clustered into the dicotyledon clade (Fig. 9c). 
286 situation also occurred in monocotyledon clade. For Oryza sativa japonica, excepting the GGPS

287 gene (orthologous to the Elaeis guineensis gene), the remaining five genes were orthologous to

288 the Zea mays genes. However, in the dicotyledon clade, Glycine max and Morus notabilis were

289 clustered on the same branches in the $D X R$ and $D X S$ gene trees, while they were on different

290 branches in phylogenetic trees of the other four genes. The DXR and HMGR genes from Populus

291 trichocarpa and Arabidopsis thaliana were more closely related than the DXR and HMGR genes

292 of the other dicotyledons. This implies that many gene duplication events have occurred 293 independently in different species, regardless of their true species trees. Still, the DXS and IPPI 294 genes of Arabidopsis thaliana, a representative dicotyledon, branched separately from the other 295 dicotyledon sequences.

297 Expression profile analyses by qRT-PCR

298 To further understand the expression profiles of the six representative genes, RNA samples from 299 three different oleoresin-yielding stages were subjected to qRT-PCR analyses. All six were 300 up-regulated in August compared to April and October (Fig. 10). Compared to expression levels 301 in April, four genes (IPPI, DXS, FPS, and DXR) increased more than 6.6-fold in August, while $302 G G P S$ and $H M G R$ increased 2.8- and 3.6-fold, respectively. Interestingly, compared to levels in 303 October, all six genes increased $~ 2$-fold in August (Fig. 10). In summary, the six representative 304 genes involved in terpenoid biosynthesis exhibited high expression levels during the high305 oleoresin-yielding stage.

\section{DISCUSSION}

308 Terpenoids play a critical role in the chemical and physical defense systems of conifers, allowing 309 them to cope with attacks from herbivores and pathogens. In addition, as important secondary 310 metabolites, terpenoids are widely used in industrial chemicals. Research on the mechanisms of 311 terpenoid biosynthesis and increasing terpenoid yields has important economic value and 
312 biological significance. In this study, transcriptome analyses were performed on secondary

313 xylem tissues of Pinus taeda. A total of 29,559,842 clean reads were obtained and assembled into

31474,402 unisequences with a mean length of $1459 \mathrm{bp}$. Only 31,586 unigenes $(42.45 \%)$ were

315 annotated by the five public databases. A total of 5,807 unigenes exhibited significant homology

316 with sequences of Picea sitchensis. However, only 450 unigenes matched proteins from Pinus

317 taeda. One possible explanation for this is the lack of available genomic information on Pinus

318 taeda in public databases. Another possibility is related to the transcript material. Many studies

319 on the genome of Pinus taeda are based on pine needles or seeds, and few studies have examined

320 secondary xylem tissues (Zimin et al., 2014; Westbrook et al., 2013). After GO annotation, a

321 mass of unigenes were identified as being involved in catalytic activity, binding, cellular

322 processes, and metabolic processes. These results indicate that oleoresin biosynthesis in Pinus

323 taeda involves many unique processes and pathways. Furthermore, KOG functional

324 classification and KEGG pathway analyses classified only 18,786 and 10,266 unigenes,

325 respectively, far less than the number of unigenes annotated by the KOG $(24,871)$ and KEGG

$326(27,942)$ databases, as many genes in these databases have not been assigned functional

327 classifications or pathways.

328 Based on the functional annotation results and previous research, a total of 372 unigenes 329 were identified as involved in oleoresin biosynthesis. These unigenes were mainly speculated to 330 encode terpenoid synthase, terpenoid backbone biosynthesis enzymes, cytochrome P450, ABC 331 transporters, pathogenesis-related proteins, alcohol dehydrogenase, and aldehyde dehydrogenase, 332 all of which have been previously reported as crucial for oleoresin biosynthesis. One previous 333 study showed that $\mathrm{ABC}$ transporter expression is related to terpenoid production in loblolly pines 334 (Materna et al., 2006). Pathogenesis-related proteins (PR5 and PR10) are commonly recognized 335 as playing important roles in plant biological defense, particularly in the fight against fungal 336 pathogens. PR5 proteins are induced by different phytopathogens in many plants and share 337 significant sequence similarity with thaumatin-like protein (Han et al., 2017). The expression of 
338 PR10 proteins is also associated with many biotic stresses (Hashimoto et al., 2004; El-Kereamy

et al., 2009). These results are consistent with previous reports that transcript levels of a PRIO

340 gene from Prunus domestica L. were significantly increased after two varieties of fungal

341 infections (Lois et al., 2000). Aldehyde dehydrogenase and alcohol dehydrogenase were reported

342 to participate in the oxidation process of dihydroartemisinic aldehyde to dihydroartemisinic acid

343 (Teoh et al., 2009) and artemisinic alcohol to artemisinic aldehyde, respectively (Polichuk et al.,

344 2010). Cytochrome P450 family proteins are one of the largest classes of proteins involved in 345 plant terpenoid secondary metabolites. In our study, a total of 67 unigenes of CYPs were identified and classified into 22 CYP subfamilies based on homology analyses. Among them

347 were many important CYP subfamilies that participate in oxidation of various terpenoids, such as the CYP720B subfamily which is involved in the two consecutive oxidations processes in the

349 formation of a series of diterpene resin acids with diterpene alcohols and aldehydes as substrates 350 (Hamberger et al., 2011; Geisler et al., 2016). However, in some cases the third oxidation step of diterpene resin acids may be catalyzed by an aldehyde dehydrogenase (Lupien et al., 1999). In addition, many other subfamilies including CYP71A (Bertea et al., 2001), CYP71B (Ginglinger et al., 2013), CYP71D (Schalk et al., 2000), CYP716A (Tamura et al., 2017), CYP701 (Itkin et al., 2016), CYP88 (Helliwell et al., 2001), CYP76B, and CYP76C (Höfer et al., 2014) have all been reported to be involved in the monooxygenation process of various terpenoids. and well-studied in many other plants. In our study, 74 unigenes were identified to participate in terpenoid backbone biosynthesis. We further analyzed six representative unigenes $(D X R, D X S$, $H M G R, I P P I, G G P S$, and FPS) previously reported to be involved in the terpenoid biosynthetic pathway. In a previous study, two types of DXS (type I and type II) were identified to catalyze

361 the first reaction of the MEP pathway and play a rate-limiting role in the production of MEP362 derived isoprenoids (Schmidt et al., 2008). In addition to DXS, DXR (Cordoba et al., 2009) and 363 IPPI (Zhao et al., 2016; Berthelot et al., 2012) also have rate-limiting roles in isopentenyl 
364 diphosphate and dimethylallyl diphosphate synthesis. It is well-accepted that HMGR is a key 365 enzyme of the MVA pathway, which catalyzes the conversion of 3-hydroxy-methylglutaryl-CoA 366 to mevalonate (Cao et al., 2010). Previous studies have suggested that over-expression of $H M G R$ 367 genes significantly increased the accumulation of terpenoids (Jayashree et al., 2018). FPP and 368 GGPP are the precursors for the biosynthesis of sesquiterpenes and diterpenes, respectively. 369 FPS is a key enzyme in isoprenoid biosynthesis, and is associated with plant growth and 370 development (Wang et al., 2018). In Pinus massoniana, the expression levels of GGPS presented 371 a substantially linear distribution when plotted against their corresponding oleoresin yields (Chen 372 et al., 2018).

373 To further examine the evolutionary relationships of these six genes in plants, molecular 374 phylogenetic trees were conducted based on their protein sequences, separately. The results 375 showed that $D X S, D X R, H M G R$, and IPPI have the same unrooted topology, and the 15 amino acid sequences were divided into three distinct monophyletic groups. This indicates that these genes originate from gene duplication after species divergence (Paszek and Górecki, 2016;

378 Baldauf et al., 2003; Krushkal et al., 2003; Kim et al., 2009). However, in the dicotyledon clade, the DXS and IPPI genes of Arabidopsis thaliana branched apart from other dicotyledon 380 sequences. This may result from incomplete lineage sorting (Chan et al., 2017). The FPS and 381 GGPS genes exhibited relatively anomalous unrooted trees. The four monocotyledon FPS genes 382 were divided into different branches, and the Zea mays GGPS gene was clustered into the dicotyledon clade. This may partly be due to the numerous unique mutations that can arise from rapidly evolving sequences (Degnan et al., 2013). Multiple sequence alignment analyses and 385 conserved motif prediction results showed that the GGPS and FPS protein sequences were less conserved compared to the other four protein sequences, and for the DXS and DXR protein 387 sequences, multiple identical motifs were discovered in different locations. This may be because upstream genes are expected to face stronger selective constraints and be more pleiotropic (Yang 
CONCLUSION

392 Transcriptome analyses of secondary xylem from loblolly pine were performed using RNA-Seq technology. A total of 74,402 unigenes were assembled from 29,559,842 high-quality reads, and 31,586 unigene sequences were annotated using five public protein databases. Based on the results of functional annotation and previous studies, 372 unigenes of terpenoid biosynthesisrelated enzymes were identified. From these, six representative genes (DXR,DXS, HMGR, IPPI, GGPS, and FPS) were selected for multiple sequence alignment analyses, conserved motif prediction, phylogenetic analyses, and expression profile analyses. The results showed that all six genes exhibited high expression levels during the high-oleoresin-yielding phase. The protein sequences of DXS and DXR were more conserved and pleiotropic than the other sequences. In addition, most of these genes originated from gene duplication after the species divergence. Taken together, our results provide an extensive perspective of regulatory factors involved in oleoresin biosynthesis of the loblolly pine, as well as a portfolio of candidate genes for future study. Further research should focus on exploring the patterns of evolutionary rates among genes of the terpenoid biosynthetic pathway.

\section{ACKNOWLEDGEMENTS}

We thanks to Science Corporation of Gene for its assistance in origin data processing and related bioinformatics analysis, and also thank Yingde Research Institute of Forestry in Guangdong Province for provide research materials.

\section{ADDITIONAL INFORMATIION AND DECLARATION}

\section{$413 \quad$ Funding}

414 This study were financed by National Key R\&D Program of China (2017YFD0600502-3) and 415 “948” program of State Forestry Administration P.R. China (2014-4-72). The funders had no role 416 in study design, data collection and analysis, decision to publish or preparation of the manuscript. 


\section{Grant Disclosures}

419 The following grant information was disclosed by the authors:

420 National Key R\&D Program of China: 2017YFD0600502-3.

421 “948” program of State Forestry Administration P.R. China: 2014-4-72.

\section{Competing Interests}

424 Jiehu Chen is employed by Science Corporation of Gene.

\section{Authors Contributions}

427 - Jipeng Mao conceived and designed the experiments, performed the experiment, analyzed the

- Zida He Performed the experiment, analyzed the data, contributed reagents/materials, authored

- Jing Hao analyzed the data, prepared figures and/or tables, authored or reviewed drafts of the paper, approved the final draft.

- Tianyi Liu analyzed the data, contributed reagents, authored or reviewed drafts of the paper, approved the final draft.

- Jiehu Chen analyzed the data, contributed analysis tools, authored or reviewed drafts of the paper. approved the final draft.

- Shaowei Huang conceived and designed the experiments, authored or reviewed drafts of the paper, approved the final draft.

\section{Data Availability}

The following information was supplied regarding data availability:

The data are represented in the Figures and Supplemental Files.

\section{REFERENCES}

An N, Ding GJ. 2010. A preliminary investigation in the main meteorological factors impacting the yield of pine resin. Journal of Mountain Agriculture and Biology. 29(27), 177-180.

Bailey TL, Elkan C.1994. Fitting a mixture model by expectation maximization to discover motifs in biopolymers. Proceedings of the 3rd International Conference on Intelligent Systems for Molecular Biology. 2, 28-36.

Baldauf SL. 2003. Phylogeny for the faint of heart: a tutorial. Trends in Genetics. 19(6), 345-351. 
452 Banerjee A, Hamberger B. 2018. P450s controlling metabolic bifurcations in plant terpene specialized metabolism. Phytochemistry Reviews. 17(1), 81-111 DOI 10.1007/s11101-017-9530-4.

Bertea CM, Schalk M, Karp F, Maffei M, Croteau R. 2001. Demonstration that menthofuran synthase of mint (Mentha) is a cytochrome P450 monooxygenase: cloning, functional expression, and characterization of the responsible gene. Archives of Biochemistry and Biophysics. 39, 279-286 DOI 10.1006/abbi.2001.2378.

Berthelot K, Estevez Y, Deffieux A, Peruch F. 2012. Isopentenyl diphosphate isomerase: A checkpoint to isoprenoid biosynthesis. Biochimie. 94(8), 1621-1634 DOI 10.1016/j.biochi.2012.03.021.

Cao X, Zong Z, Ju X, Sun Y, Dai C, Liu Q, Jiang JH. 2010. Molecular cloning, characterization and function analysis of the gene encoding HMG-CoA reductase from Euphorbia Pekinensis Rupr. Molecular Biology Reports. 37(3), 1559-1567 DOI 10.1007/s11033-009-9558-7.

Chan YB, Ranwez V, Scornavacca C. 2017. Inferring incomplete lineage sorting, duplications, transfers and losses with reconciliations. Journal of Theoretical Biology. 432, 1 DOI 10.1016/j.jtbi.2017.08.008.

Chang S, Puryear J, Caimey J. 1993. A simple and efficient method for isolating RNA from pine trees. Plant Molecular Biology Reporter. 11, 113-116.

Chen B, Xiao Y, Li H, Liu H, Jia J, Chao N, Gai Y, Jiang X. 2018. Cloning and characterization of geranylgeranyl diphosphate synthetase from Pinus massoniana and its correlation with resin productivity. Journal of Forestry Research. 2, 1-10 DOI 10.1007/s11676-017-0443-2.

Chen H, Yuan F. 2002. Resistance of host trees and existance strategy evolution of bark beetles. Scientia Silvae Sinicae. 38 (5), 147-151.

Conesa A, Terol J, Robles M. 2005. Blast2GO: a universal tool for annotation, visualization and analysis in functional genomics research. Bioinformatics. 21 (18), 3674-3676 DOI 10.1093/bioinformatics/bti610.

Cordoba E, Salmi M, León P. 2009. Unravelling the regulatory mechanisms that modulate the MEP pathway in higher plants. Journal of Experimental Botany. 60 (10), 2933 DOI 10.1093/jxb/erp190.

Dafoe NJ, Zamani A, Ekramoddoullah AKM, Lippert D, Bohlmann J, Constabel CP. 2009. Analysis of the Poplar phloem proteome and its response to leaf wounding. Journal of Proteome Research. 8, 2341-2350 DOI 10.1093/jxb/erp190.

Degnan JH. 2013. Anomalous unrooted gene trees. Systematic Biology. 62(4), 574-590 DOI 10.1093/sysbio/syt02.

Drew DP, Dueholm B, Weitzel C, Zhang Y, Sensen CW, Simonsen HT. 2013. Transcriptome Analysis of Thapsia laciniata Rouy provides insights into terpenoid biosynthesis and diversity in Apiaceae. International Journal of Molecular Sciences. 14(5), 9080-9098 DOI 10.3390/ijms14059080.

EL-kereamy A, Jayasankar S, Taher A, Errampall D, Paliyath G. 2009. Expression analysis of a plum pathogenesis related 10 (PR10) protein during brown rot infection. Plant Cell Reports. 28, 95-102 DOI 10.1007/s00299-008-0612-z. 
489 Eisenreich W, Schwarz M, Cartayrade A, Arigoni D, Zenk MH, Bacher A. 1998. The deoxyxylulose phosphate pathway of terpenoid biosynthesis in plants and microorganisms. Journal of Biological Chenmistry. 5, R221-R233 DOI 10.1016/S1074-5521(98)90002-3.

Foucart C, Paux E, Ladouce N, Grima-Pettenati J, Sivadon P. 2006. Transcript profiling of a xylem vs phloem cDNA subtractive library identifies new genes expressed during xylogenesis in Eucalyptus. New Phytolgist. 170 (4), 739-752 DOI 10.1111/j.1469-8137.2006.01705.x.

Geisler K, Jensen NB, Yuen MM, Madilao L, Bohlmann J. 2016. Modularity of conifer diterpene resin acid biosynthesis: P450 enzymes of different CYP720B clades use alternative substrates and converge on the same products. Plant Physiology. 171, 152-164 DOI 10.1104/pp.16.00180.

Ginglinger JF, Boachon B, Höfer R, Paetz C, Kollner TG, Miesch L, Lugan R, Baltenweck R, Mutterer J, Ullmann, P, Beran F, Claudel P, Verstappen F, Fischer MJC, Karst F, Bouwmeester H, Miesch M, Schneider B, Gershenzon J, Ehlting J, Werck-Reichhart D. 2013. Gene coexpression analysis reveals complex metabolism of the monoterpene alcohol linalool in Arabidopsis flowers. Plant Cell. 25, 4640-4657 DOI 10.1105/tpc.113.117382.

Haas BJ, Papanicolaou A, Yassour M, Grabher M, Blood PD, Bouden J. 2013. De novo transcript sequence reconstruction from RNA-seq using the Trinity platform for reference generation and analysis. Nature Protocols. 8, 1494-1512 DOI 10.1038/nprot.2013.084.

Hamberger B, Ohnishi T, Hamberger B, Seguin A, Bohlmann J. 2011. Evolution of diterpene metabolism: Sitka spruce CYP720B4 catalyzes multiple oxidations in resin acid biosynthesis of conifer defense against insects. Plant Physiology. 157, 1677-1695 DOI 0.1104/pp.111.185843.

Han X, He X, Qiu W, Lu Z, Zhang Y. 2017. Pathogenesis-related protein PR10 from Salix matsudana koidz exhibits resistance to salt stress in transgenic Arabidopsis thaliana. Environmental \& Experimental. 141, 74-82 DOI 10.1016/j.envexpbot.2017.07.008.

Hashimoto M, Kisseleva L, Shinichiro S, Furukawa T, Komatsu S, Koshiba T. 2004. A novel rice PR10 protein RSOs PR10; Specifically induced in roots by biotic and abiotic stresses possibly via the jasmonic acid signaling pathway. Plant Cell Physiology. 45 (5), 550-559.

Helliwell CA, Chandler PM, Poole A, Dennis ES, Peacock WJ. 2001. The CYP88A cytochrome P450, ent-kaurenoic acid oxidase, catalyzes three steps of the gibberellin biosynthesis pathway. Proceedings of the National Academy of Sciences of the United States of America. 98, 2065-2070 DOI 10.1073ypnas.041588998.

Höfer R, Boachon B, Renault H, Gavira C, Miesch L, Iglesias J, Ginglinger JF, Allouche L, Miesch M, Grec S, Larbat R, Werck-Reichhart D. 2014. Dual function of the cytochrome P450 CYP76 family from Arabidopsis thaliana in the metabolism of monoterpenols and phenylurea herbicides. Plant Physiology. 166, 1149-1161 DOI 10.1104/pp.114.244814.

Itkin M, Davidovichrikanati R, Cohen S, Portnoy V, Doronfaigenboim A, Oren E, Filich S, Tzuri G, Baranes N, Shen S, Petreikov M. 2016. The biosynthetic pathway of the nonsugar, high-intensity sweetener mogroside v from Siraitia grosvenorii. Proceedings of the National Academy of Sciences 
of the United States of America. 113(47), DOI E7619. 10.1073/pnas.1804875115.

Jayashree R, Nazeem PA, Rekha K, Sreelatha S, Thulaseedharana A, Krishnakumara R, Kala RG, Vineetha M, IEDA P, Jinud U, Venkatachalamad P. 2018. Over-expression of 3-hydroxy-3methylglutaryl-coenzyme A reductase 1 (hmgrl) gene under super-promoter for enhanced latex biosynthesis in rubber tree (Hevea brasiliensis Muell. Arg.). Plant Physiology \& Biochemistry. 2018, 127-414 DOI 10.1016/j.plaphy.2018.04.011.

Jasinski M, Stukkens Y, Degand H, Purnelle B, Marchard-Brynaert J, Boutry M. 2001. A plant plasma membrane ATP bingding cassette-type transporter is involved in antifungal terpenoid secretion. Plant Cell. 13, 1095-1107.

Kim YB, Kim SM, Kang MK, Kuzuyama T, Lee JK, Park SC, Shin SC, Kim SU. 2009. Regulation of resin acid synthesis in Pinus densiflora by differential transcription of genes encoding multiple 1deoxy-D-xylulose 5-phosphate synthase and 1-hydroxy-2-methyl-2-(E)-butenyl 4-diphosphate reductase genes. Tree Physiology. 29,737-749 DOI 10.1093/treephys/tpp002.

Kumar S, Stecher G, Tamura K. 2016. MEGA7: molecular evolutionary genetics analysis version 7.0 for bigger datasets. Molecular Biology and Evolution. 33,1870-1874 DOI 10.1093/molbev/msw054.

Krushkal J, Pistilli M, Ferrell KM, Souret FF, Weathers PJ. 2003. Computational analysis of the evolution of the structure and function of 1-deoxy- D -xylulose-5-phosphate synthase, a key regulator of the mevalonate-independent pathway in plants. Gene. 313, 127-138 DOI 10.1016/S0378-119(03)00668-1.

Liu QH, Zhou Z, Wei Y, Shen D, Feng Z, Hong S. 2015. Genome-wide identification of differentially expressed genes associated with the high yielding of oleoresin in secondary xylem of masson pine (Pinus massoniana L.) by Transcriptomic analysis. PLoS One. 7, 1-16 DOI 10.1371/journal.pone.0132624.

Livak KJ, Schmittgen TD. 2001. Analysis of relative gene expression data using real time quantitative PCR and the 2- $\Delta \Delta$ Ct method. Methods. 25, 402-408 DOI 10.1006/meth.2001.1262.

Lois LM, Gallego F, Campos N. 2000. Carotenoid biosynthesis during tomato fruit development: regulatory role of 1-deoxy-d-xylulose 5-phosphate synthase. Plant Journal. 22 (6), 503-513.

Lu M, Krutovsky KV, Nelson CD, West JB, Reilly NA, Loopstra CA. 2017. Association genetics of growth and adaptive traits in loblolly pine (Pinus taeda, L.) using whole-exome-discovered polymorphisms. Tree Genetics \& Genomes. 13(3), 57 DOI 10.1007/s11295-017-1140-1.

Lupien S, Karp F, Wildung M, Croteau R. 1999. Regiospecific cytochrome P450 limonene hydroxylases from mint (Mentha) species: cDNA isolation, characterization, and functional expression of (-)-4S-limonene-3- hydroxylase and (-)-4S-limonene-6-hydroxylase. Archives of Biology and Biochemistry. 368, 181-192 DOI 10.1006/abbi.1999.1298.

Lu Y, Rausher MD. 2003. Evolutionary rate variation in anthocyanin pathway genes. Molecular Biology \& Evolution. 20 (11), 1844-1853 DOI 10.1093/molbev/msg197.

Materna SC, Ashby-Howard M, Gray RF, Cameron AR, Davidson EH. 2006. The C2H2 zinc finger 
563 genes of strongylocentrotus purpuratus and their expression in embryonic development.

564

565

566

567

568

569

570

571

572

573

574

575

576

577

578

579

580

581

582

583

584

585

586

587

588

Developmental Biology. 300, 108-120 DOI 10.1016/j.ydbio.2006.08.032.

Miller B, Oschinski C, Zimmer W. 2001. First isolation of anisoprene synthase gene from poplar and successful expression of the gene in Escherichia coli. Planta. 213, 483-487.

Niu J, Hou X, Fang C, An JY, Ha D. 2015. Transcriptome analysis of distinct Lindera glauca tissues revealed the differences in the unigenes related to terpenoid biosynthesis. Gene. 559 (1), 22-30 DOI 10.1016/j.gene.2015.01.002.

Olatunde G, Fasina O, McDonald T, Adhikari S, Duke S. 2017. Moisture effect on fluidization behavior of loblolly pine Wood grinds. Biomass Conversion and Biorefinery. 7, 207-220.

Pandey A, Swarnkar V, Pandey T, Srivastava P, Kanojiya S, Mishra DK, Tripathi V. 2016. Transcriptome and metabolite analysis reveal candidate genes of the cardiac glycoside biosynthetic pathway from calotropis procera. Science Reports. 6, 34464 DOI 10.1038/srep34464.

Polichuk DR, Zhang Y, Reed DW, Schmid, JF, Covello PS. 2010. A glandular trichome-specific monoterpene alcohol dehydrogenase from Artemisia annua. Phytochemistry. 71, 1264-1269 DOI 10.1016/j.phytochem.2010.04.026.

Paszek J, Górecki P. 2016. Genomic duplication problems for unrooted gene trees. Bmc Genomics. 17 (1), 15 DOI 10.1186/s12864-015-2308-4.

Rodríguez-Concepcion M and Boronat A. 2015. Breaking new ground in the regulation of the early steps of plant isoprenoid biosynthesis. Current Opinion in Plant Biology. 25:17-22 DOI 10.1016/j.pbi.2015.04.001.

Rohmer M. 1999. The discovery of a mevalonate-independent pathway for isoprenoid biosynthesis in bacteria, algae and higher plants. Natural Product Reports. 16, 565-574 DOI:10.1039/A709175C.

Schalk M, Croteau R. 2000. A single amino acid substitution (F363I) converts the regiochemistry of the spearmint (-)-limonene hydroxylase from a C6- to a C3-hydroxylase. Proceedings of the National Academy of Sciences of the United States of America. 97, 11948-11953.

Schmidt A, Gershenzon J. 2008. Cloning and characterization of two different types of geranyl diphosphate synthases from Norway spruce (Picea abies). Phytochemistry. 69, 4-57 DOI 10.1016/j.phytochem.2007.06.022.

Scott AC, Anderson JM, Anderson HM. 2004. Evidence of plant-insect interactions in the upper Triassic Molteno formation of South Africa. Journal of the Geological Society. 161, 401-410 DOI 10.1144/0016-764903-118.

Su X, Li Q, Chen S, Dong C, Hu Y, Yin L. 2016. Analysis of the transcriptome of Isodon rubescens and key enzymes involved in terpenoid biosynthesis. Biotechnology \& Biotechnological Equipment. 30 (3), 1-10 DOI 10.1080/13102818.2016.1146086.

Tamura K, Seki H, Suzuki H, Kojoma M, Saito K, Muranaka T. 2017. CYP716A179 functions as a triterpene C-28 oxidase in tissue-cultured stolons of Glycyrrhiza uralensis. Plant Cell Reports. 36, 437-445 DOI 10.1007/s00299-016-2092-x. 
600 Teoh KH, Polichuk DR, Reed DW. 2009. Molecular cloning of an aldehyde dehydrogenase implicated

601

602

603

604

605

606

607

608

609

610

611

612

613

614

615

616

617

618

619

620 in artemisinin biosynthesis in Artemisia annua. Botany. 87, 635-642 DOI 10.1139/B09-032.

Trapp S, Croteau R. 2001. Defensive resin biosynthesis in conifers. Annual Review of Plant Physiology and Plant Molecular Biology. 52, 689-724.

Wang L, Jing T, Li T, Du H, Wuyun T. 2018. Identification and expression analysis of the Eucommia ulmoides, farnesyl diphosphate synthase gene family to reveal the key gene involved in rubber biosynthesis. Acta Physiologiae Plantarum. 40(1), 11 DOI 10.1007/s11738-017-2588-1.

Westbrook JW, Resende MF, Munoz P, Walker AR, Wegrzyn JL, Nelson CD. 2013. Association genetics of oleoresin flow in loblolly pine: discovering genes and predicting phenotype for improved resistance to bark beetles and bioenergy potential. New Phytologist. 199, 89-100 DOI 10.1111/nph.12240.

Xu Z, Xia L, Chen M, Cheng X, Zhang R, Li L. 2007. Isolation and molecular characterization of the Triticum aestivum L.ethylene-responsive factor 1 (TaERF1) that increases multiple stress tolerance. Plant Molecular Biology. 65, 719-732 DOI 10.1007\%2Fs11103-007-9237-9.

Yamada Y, Kuzuyama T, Komatsu M, Shin-ya K, Omura S, Cane DE, Ikeda H. 2015. Terpene synthases are widely distributed in bacteria. Proceedings of the National Academy of Sciences of the United States of America. 112, 857-862 DOI 10.1073/pnas.1422108112.

Yang Y, Zhang F, Song G. 2009. Evolutionary rate patterns of the Gibberellin pathway genes. Bmc Evolutionary Biology. 9(1), 206 DOI 10.1186/1471-2148-9-206.

Ye J, Fang L, Zheng H, Zhang Y, Chen J, Zhang Z, Wang J, Li S, Li R, Bolund L, Wang J. 2006. WEGO: a web tool for plotting GO annotations. Nucleic Acids Research. 34(Web Server issue), W293-W297b DOI 10.1093/nar/gk1031.

Zhao L, Wang G, Josine TL, Wu J, Diao J. 2016. Cloning and heterologous expression of isopentenyl diphosphate isomerase gene from Lycium chinense. Journal of Plant Biochemistry \& Biotechnology. 25 (1), 40-48 DOI 10.1007\%2Fs13562-015-0306-x.

Zimin AV, Stevens KA, Crepeau MW, Holtz-Morris A, Koriabine M, Marcais G, Puiu D, Roberts M, Wegrzyn JL, de Dong PJ, Neale DB, Salzberg SL, Yorke JA, Langley CH. 2014. Sequencing and assembly of the 22-gb loblolly pine genome. Genetics. 196 (3), 875-90 DOI 10.1534/genetics.113.159715.

Zulak KG, BohImanu J. 2010. Terpenoid biosynthesis and specialized vascular cells of conifers defense. Journal of Integrative Plant Biology. 52 (1), 86-97 DOI 10.1111/j.1744-7909.2010.00910.x. 


\section{Figure 1}

Oleoresin and RNA samples collection methods.

a: Artificial collection of oleoresin in South China. b: Sampling site and method of secondary xylem tissue.

a.

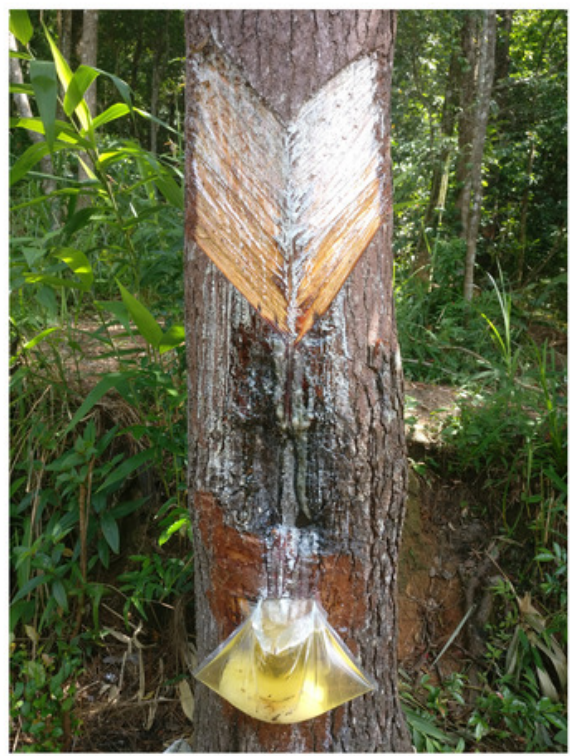

b.

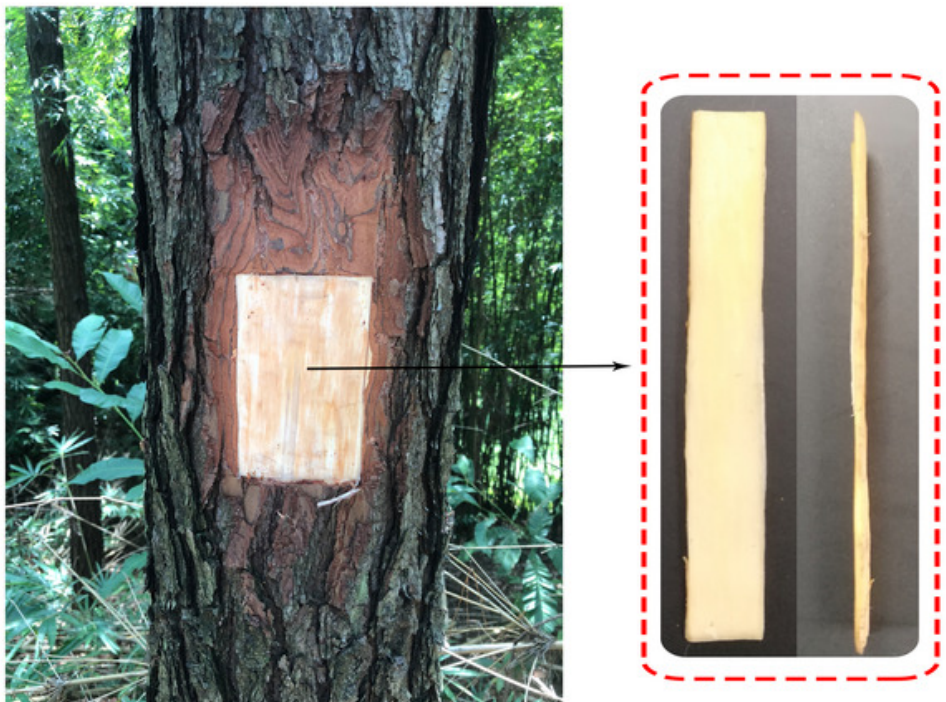


Figure 2

Length distribution

The length distribution of 74,402 assembled unigenes in secondary xylem of Pinus taeda.

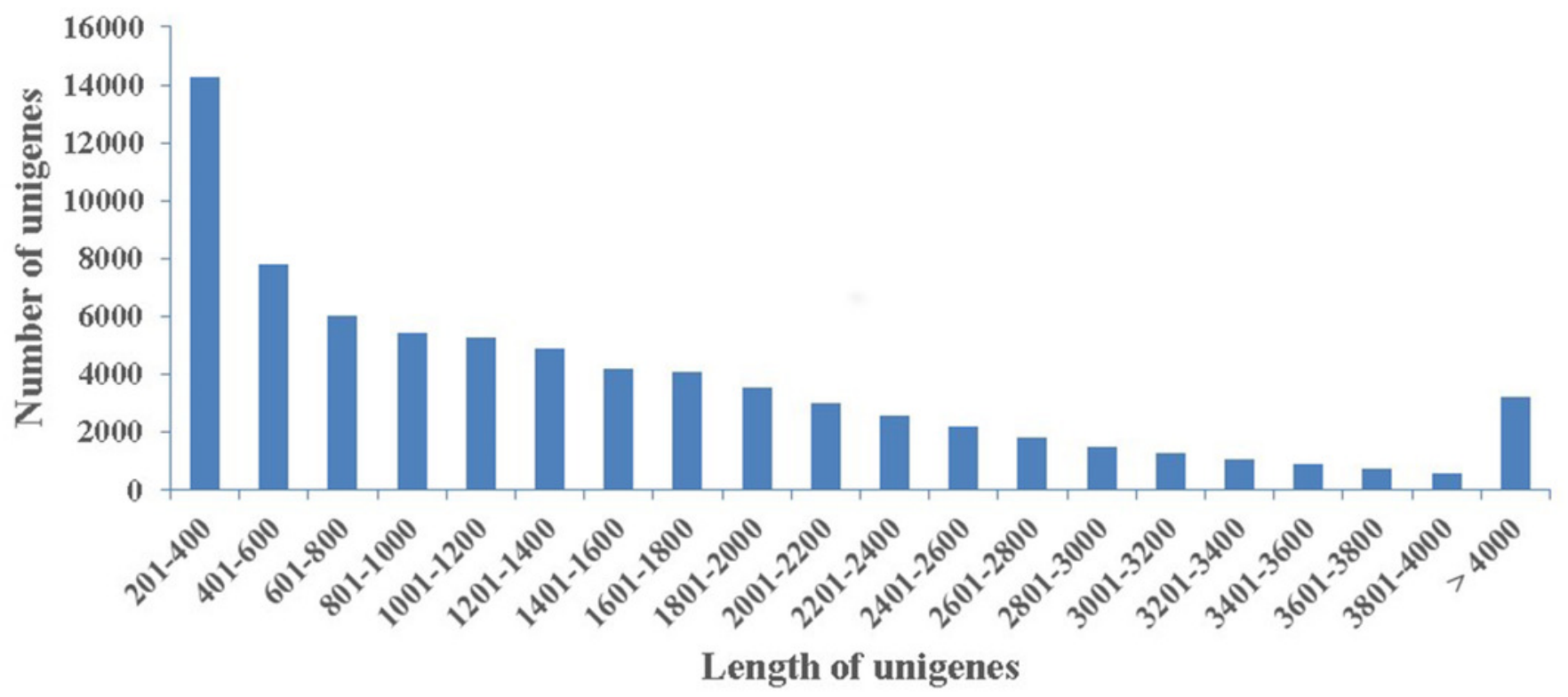


Figure 3

Venn diagram

The venn diagram of 31,586 unigenes from five public database.

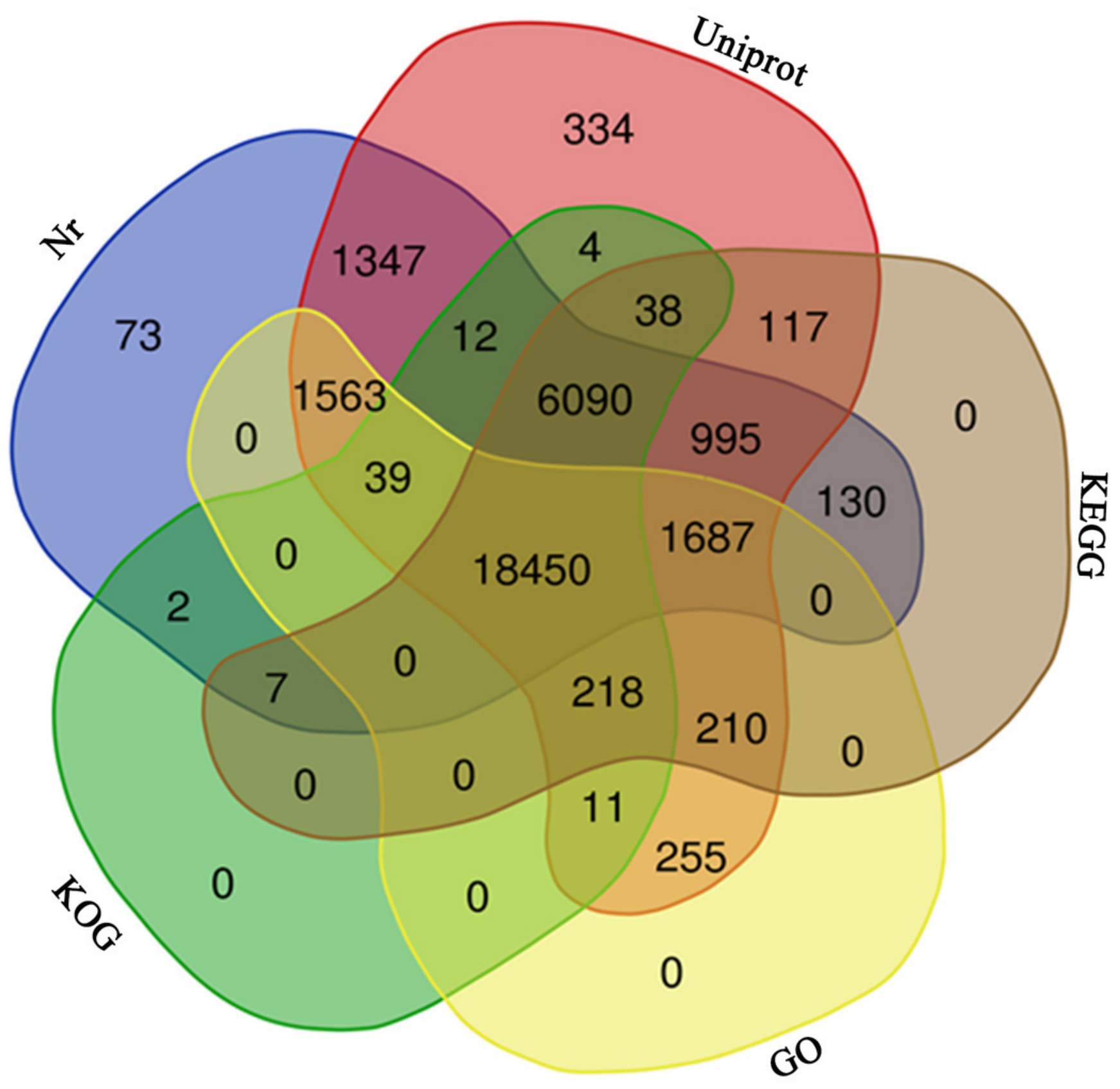




\section{Figure 4}

\section{Assembled unigenes were functionally classificated by Gene Ontology categorization.}

The unigenes corresponded to three main categories: biological process,cellular component, and molecular function.

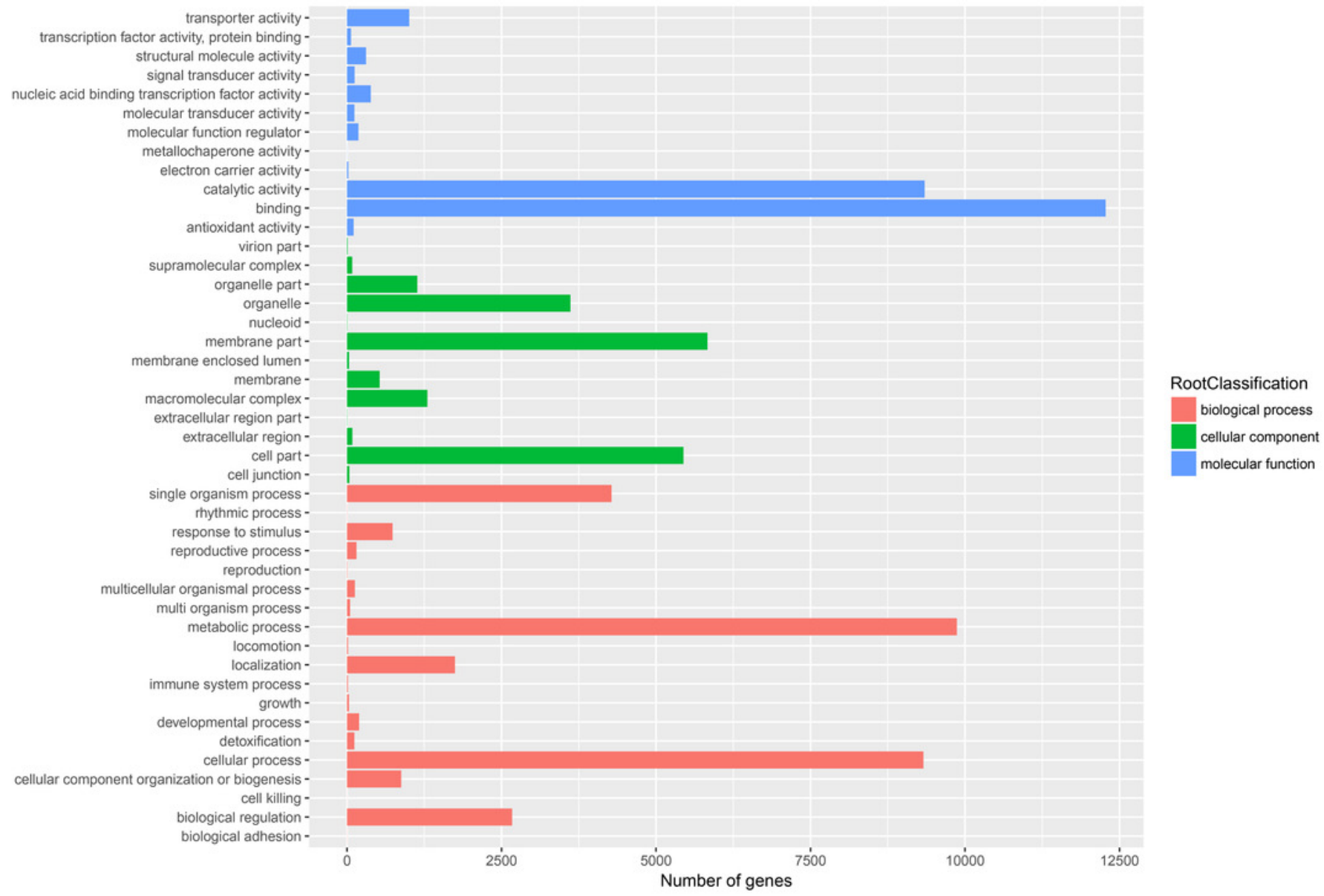




\section{Figure 5}

\section{KOG functional classification of all unigenes.}

Atotal of 18,786 unigenes showed significant similarity to the sequences in KOG databases and were clustered into 25 categories.

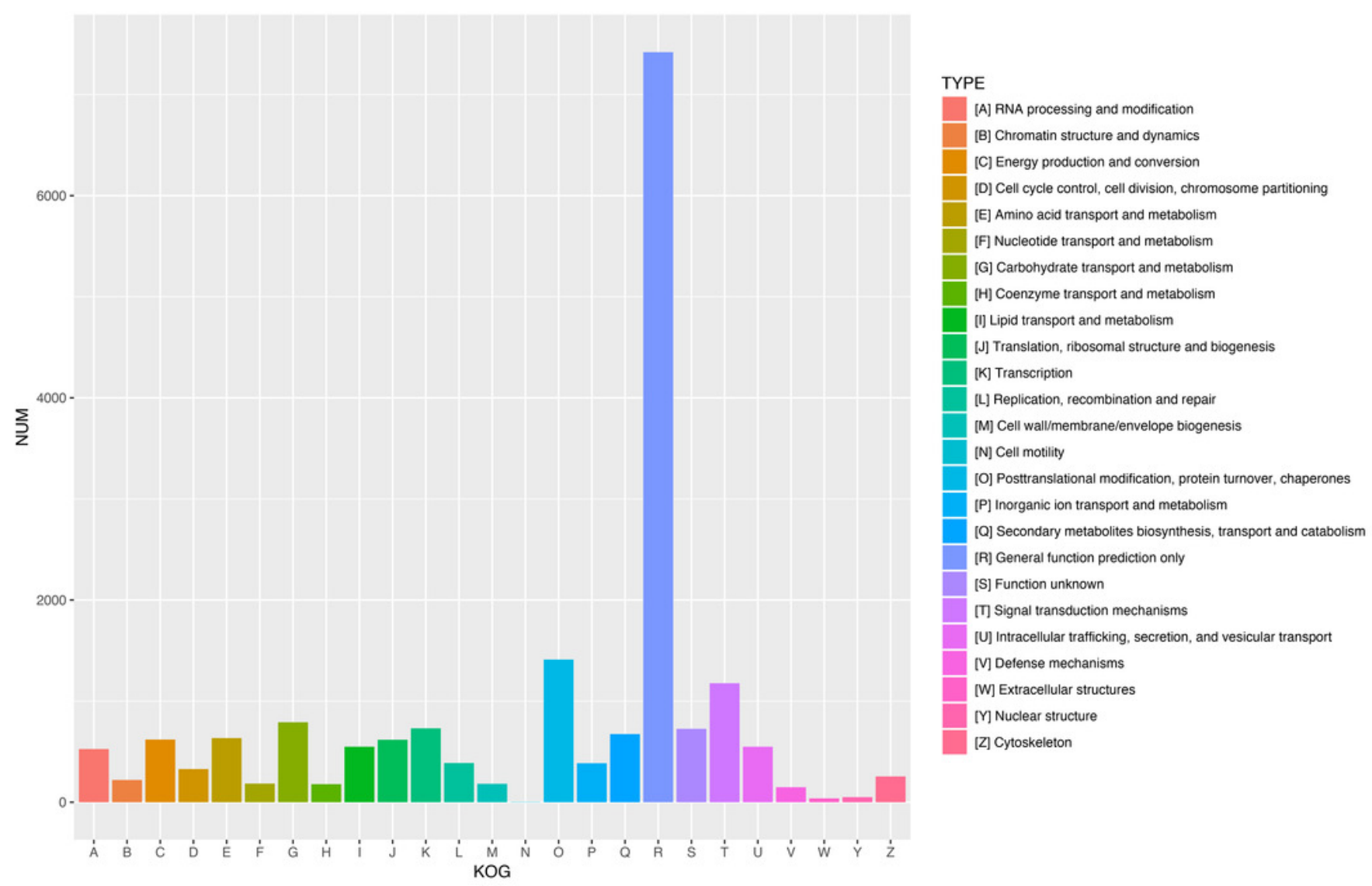




\section{Figure 6}

\section{Assembled unigenes were functionally classificated by KEGG classification.}

The unigenes corresponded to five main categories: Cellular processes, Environmental information Processing, Genetic information Processing, Metabolism and Organismal Systems.

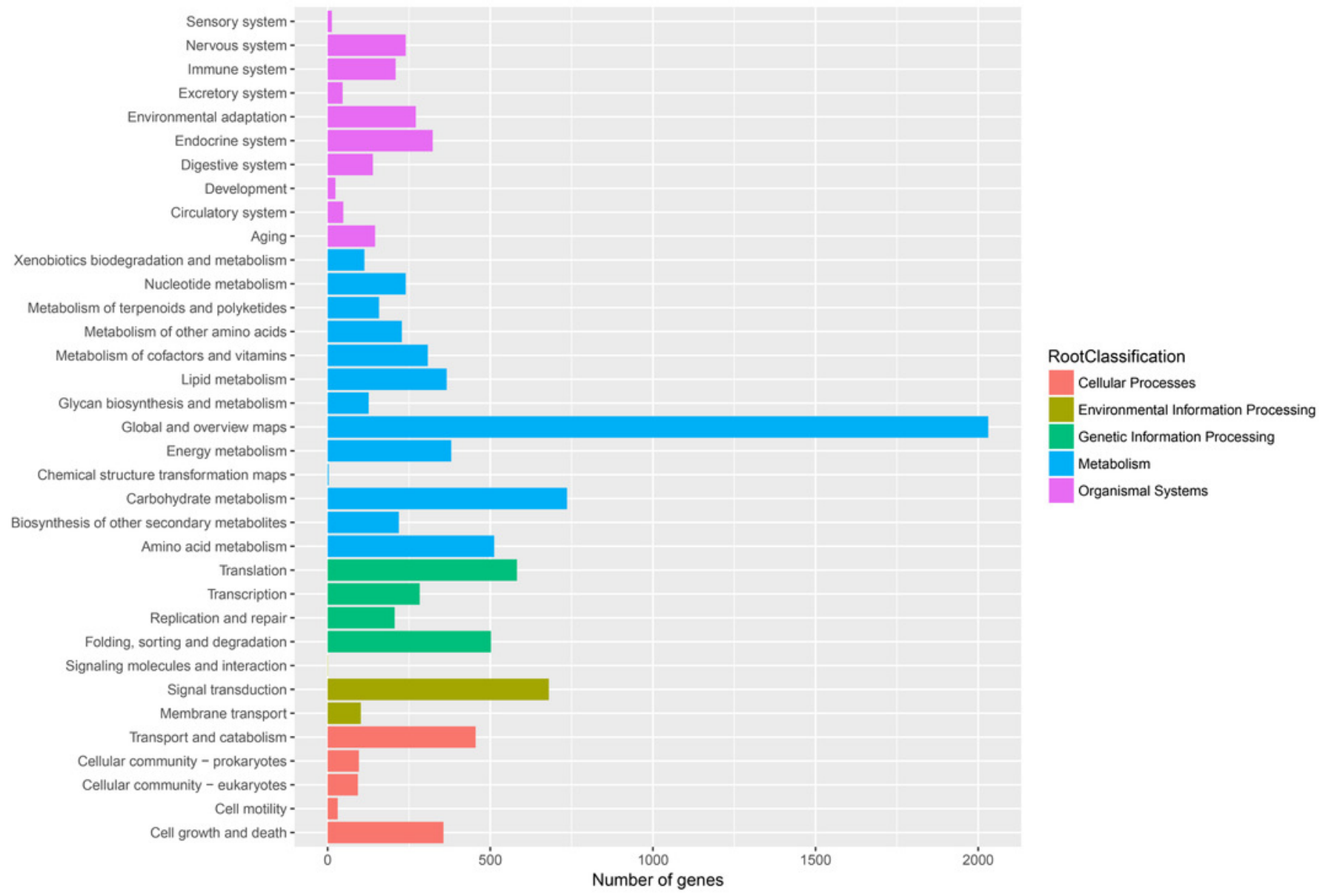




\section{Figure 7}

\section{Distribution of conserved motifs of DXR protein sequences in 15 plant species}

Phylogenetic relationship were displayed on left, and blue, red and green lines represented gymnosperm, monocotyledon and dicotyledon, respectively. Each motif is represented by a colored box and a number, and the same number with differ letters represented the identical motif located in different sites.

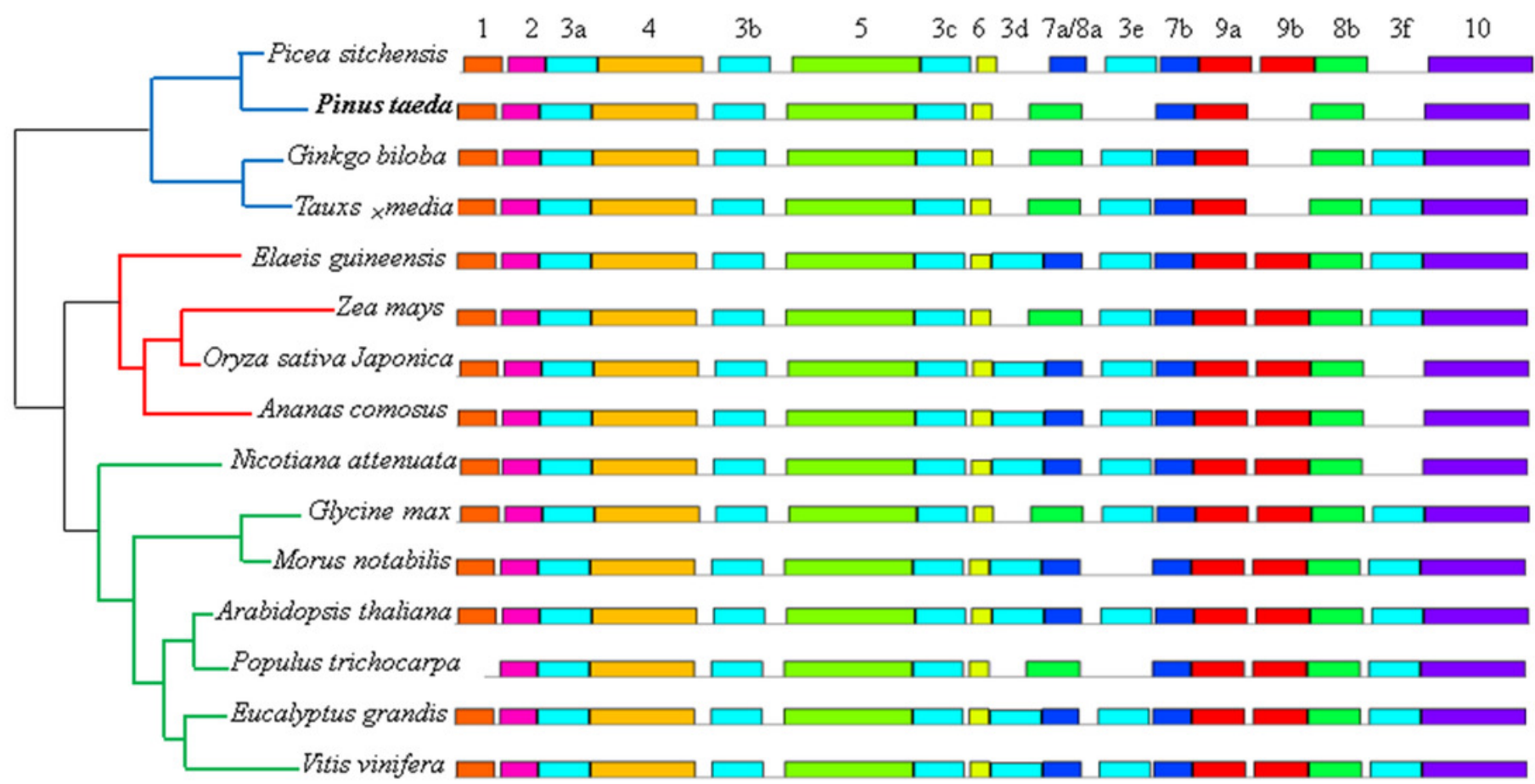


Figure 8

Biosynthetic pathway of terpenoids (adapted from Zulak et al., 2010; Liu et al., 2015).

The number of unigenes homologous to gene families encoding these enzymes was provided in parentheses.

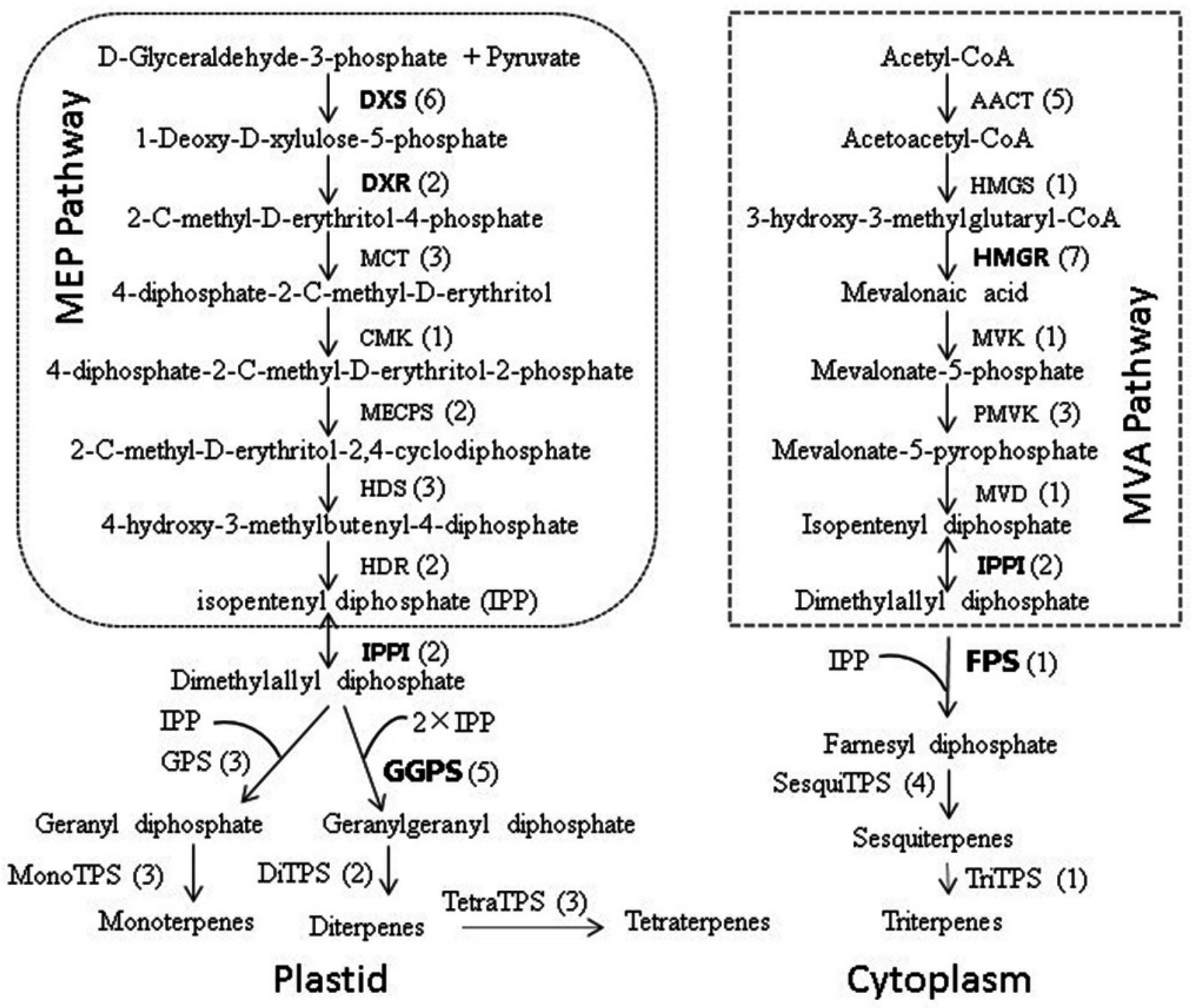




\section{Figure 9}

Bayesian phylogenetic analysis of the DXR, DXS, HMGR, IPPI, GGPS and FPS genes in 15 plant species.

They bootstrap values were given in present and the scale bar indicate $0.05,0.05,0.1,0.2,0.2$ and 0.05 substitutions per site, respectively. a: phylogenetic tree of DXR gene with JTT+I+G model, b: phylogenetic tree of DXS gene with JTT+I+G model, c: phylogenetic tree of GGPS gene with $L G+G+F$ model, $d$ :

phylogenetic tree of FPS gene with $L G+I+G$ model, e: phylogenetic tree of HMGR gene with JTT+G+F model, f: phylogenetic tree of IPPI gene with JTT+I+G model. 

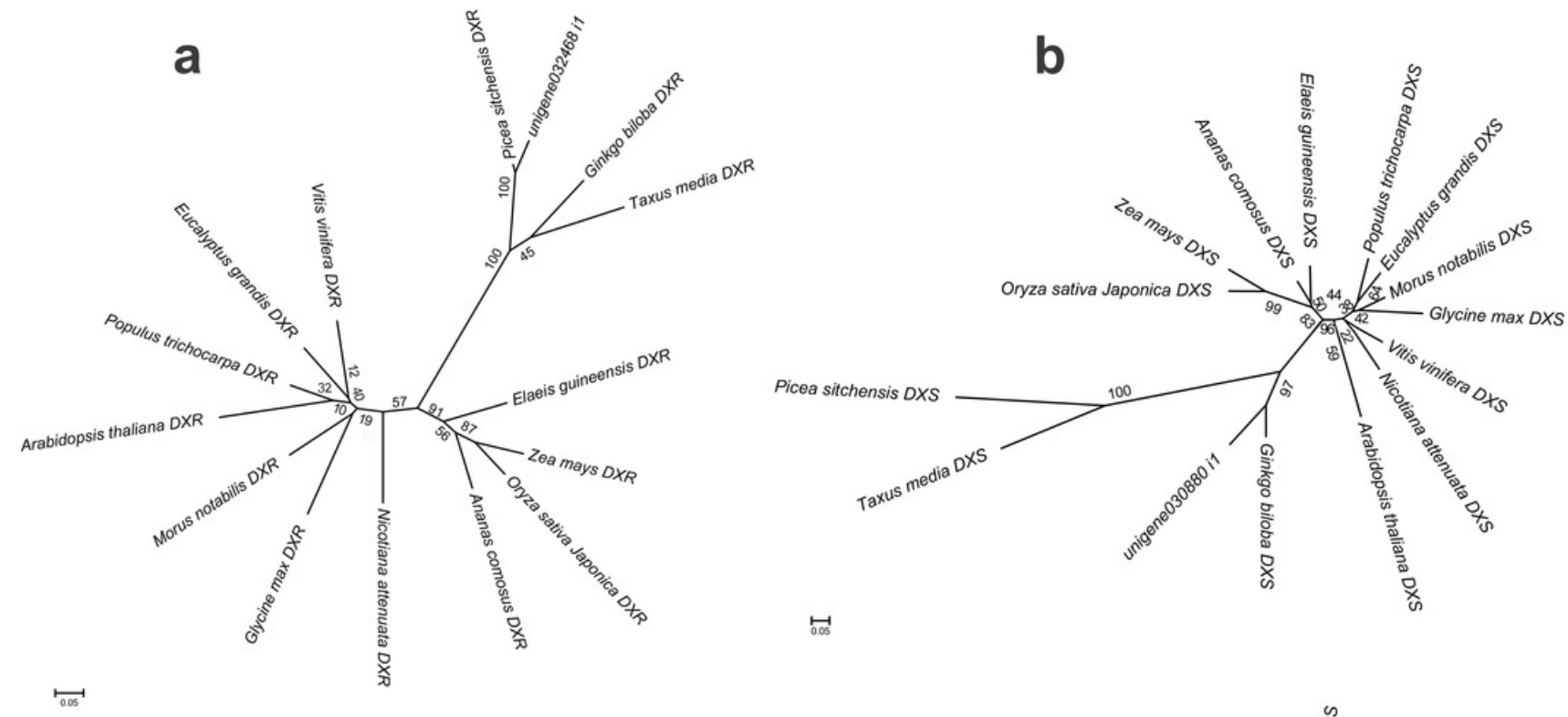

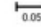
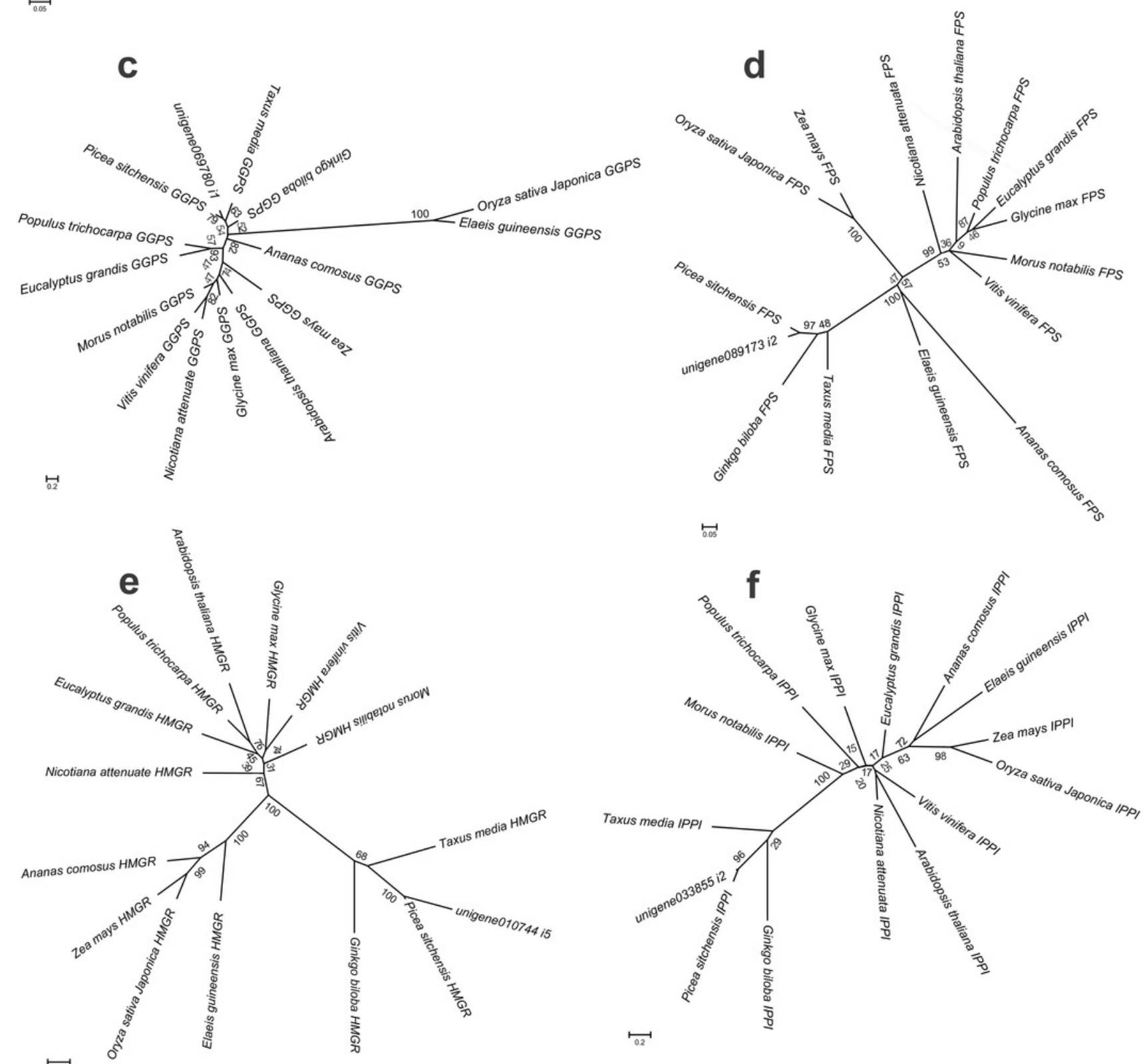

${ }^{\circ}$ Peerj reviewing PDF | (2018:08:30773:1:0:NEW 6 Nov 2018) 
Figure 10

Quantitative RT-PCR analysis of six candidate genes in three different oleoresin-yielding stages (Apr., Aug. and Oct.).

Relative expression levels of qRT-PCR calculated using Actin as the internal control were shown in the yaxis. Error bars represent SD of the mean for three biological replicates.
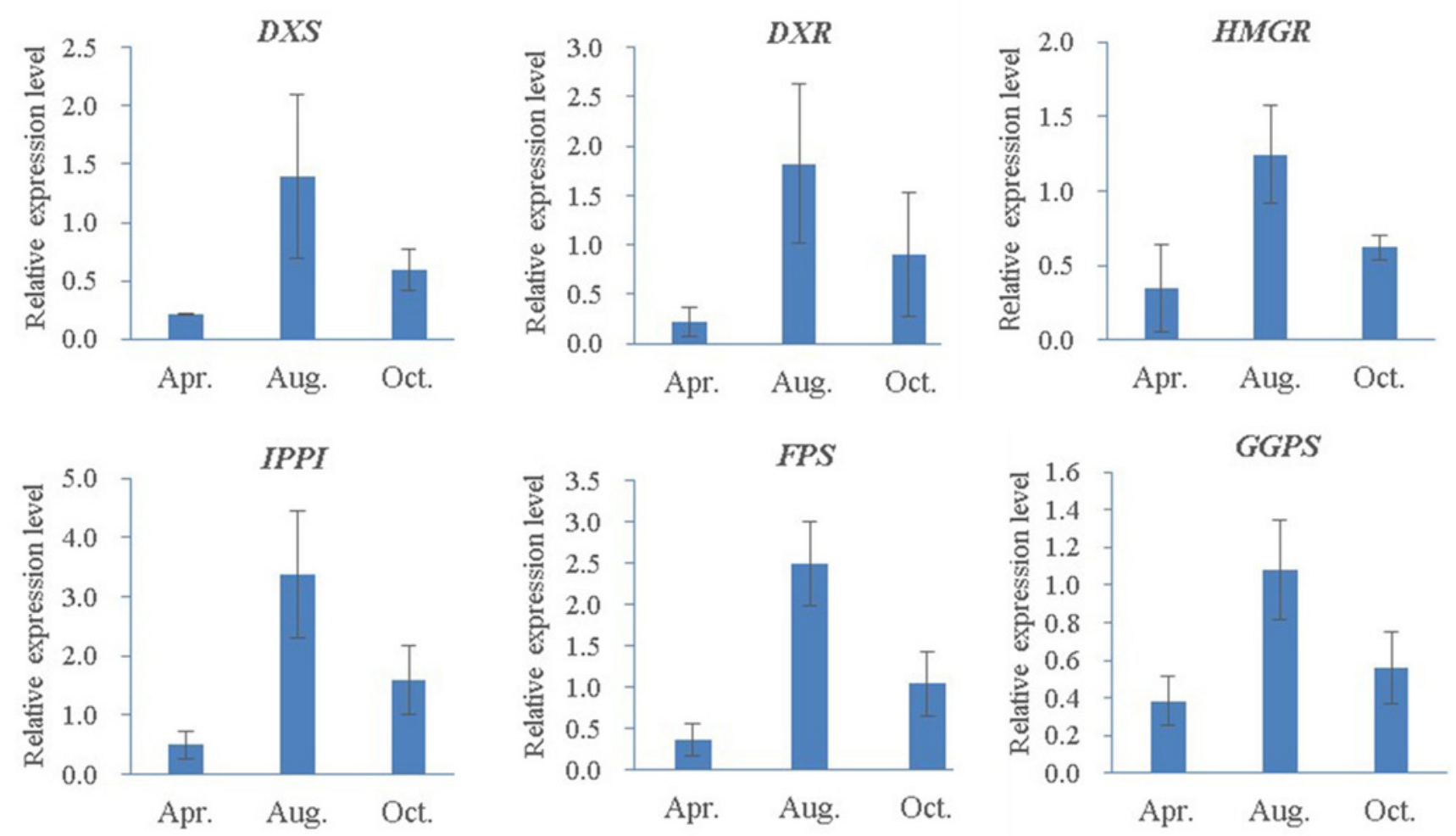


\section{Table $\mathbf{1}$ (on next page)}

Summary of unigenes functional annotation. List of 74,402 unigenes against five public database. 


\begin{tabular}{ccc}
\hline Database & Number of annotated & Percentage of annotated unigenes (\%) \\
& unigenes & $30.15 \%$ \\
\hline Gene Ontology (GO) & 22,433 & $33.43 \%$ \\
euKaryotic Orthologous & & \\
Groups (KOG) & 24,871 & $37.56 \%$ \\
Kyoto Encyclopedia of & & \\
Genes and Genomes (KEGG) & 27,942 & $40.85 \%$ \\
Non-redundant (Nr) & 30,395 & $42.16 \%$ \\
UniProt & 31,370 & \\
\hline
\end{tabular}

1

2 


\section{Table 2 (on next page)}

List of 13 terpenoid synthase unigenes. Summary of 13 terpenoid synthase unigenes and their functional annotation information. 


\begin{tabular}{|c|c|c|c|c|}
\hline Classification & Unigene_ID & Unigene Length (bp) & $\mathrm{Nr}$ _annotation & Accession number \\
\hline \multirow{3}{*}{ Monoterpenoid } & unigene065907_i1 & 387 (partial) & Carene synthase & Q84SM8.1 \\
\hline & unigene 056578 i1 & 2238 (partial) & (-)-limonene synthase & AAS47694.1 \\
\hline & unigene 003908 i1 & 2265 (complete) & $(+)$-alpha-pinene synthase & Q84KL3.1 \\
\hline \multirow{3}{*}{ Diterpenoid } & unigene108418_i10 & 3432 (complete) & farnesene synthase & ADH29869.1 \\
\hline & unigene044752_i1 & 251 (partial) & alpha-humulene synthase & ADZ45513.1 \\
\hline & unigene108420_i1 & 360 (partial) & alpha-bisabolene synthase & AAS47689.1 \\
\hline \multirow{3}{*}{ Sesquiterpenoid } & unigene057627_i12 & 1206 (complete) & levopimaradiene synthase & M4HXU6.1 \\
\hline & & & & \\
\hline & unigene 011223 i2 & 1309 (complete) & momilactone a synthase & OIT37089.1 \\
\hline \multirow[t]{2}{*}{ Triterpenoid } & unigene 087027 i1 & 2055 (complete) & squalene synthase & AHI96421.1 \\
\hline & unigene037971_i1 & 3162 (complete) & cycloartenol synthase & AAG44096.1 \\
\hline \multirow[t]{2}{*}{ Tetraterpenoid } & unigene082221_i1 & 782 (partial) & Trans-phytoene synthase & ABR16280.1 \\
\hline & unigene082222_i1 & 714 (partial) & Cis-phytoen synthase & ABR16198.1 \\
\hline
\end{tabular}




\section{Table 3(on next page)}

The protein sequences information of the six representative genes in 14 plant species.

$\mathrm{Nr}$ ID: accession number in $\mathrm{Nr}$ dabtabase, Chr: chromosome location, ' ' represented unknown chromosome location. 


\begin{tabular}{|c|c|c|c|c|c|c|c|c|c|c|c|c|}
\hline \multirow{3}{*}{ Species } & \multicolumn{12}{|c|}{ Gene } \\
\hline & \multicolumn{2}{|l|}{ DXR } & \multicolumn{2}{|l|}{ DXS } & \multicolumn{2}{|l|}{ HMGR } & \multicolumn{2}{|l|}{ IPPI } & \multicolumn{2}{|l|}{ GGPS } & \multicolumn{2}{|l|}{ FPS } \\
\hline & $\mathrm{Nr}$ ID & $\mathrm{Chr}$ & Nr_ID & $\mathrm{Chr}$ & $\mathrm{Nr}$ ID & $\mathrm{Chr}$ & $\mathrm{Nr}$ IID & $\mathrm{Chr}$ & $\mathrm{Nr}$ ID & $\mathrm{Chr}$ & $\mathrm{Nr}$ ID & $\mathrm{Chr}$ \\
\hline Picea sitchensis & ACN40563.1 & . & ACN39837.1 & . & ACN40476.1 & . & ACN41037.1 & . & ACN40956.1 & . & ACN40171.1 & . \\
\hline Ginkgo biloba & AAR95700.1 & . & AAR95699.1 & . & AAU89123.1 & . & ACU56979.1 & . & AAQ72786.1 & . & AAR27053.1 & \\
\hline Taxus $\times$ media & AAU87836.1 & . & AAS89342.1 & . & AAQ82685.1 & . & ALA48967.1 & . & AFD32422.1 & . & AAS19931.1 & . \\
\hline Zea mays & ONM30686.1 & 1 & ABP88135.1 & 5 & XP_008677153.1 & 4 & XP_008649644.1 & 8 & NP_001183930.1 & 2 & NP_001105039.1 & 8 \\
\hline Elaeis guineensis & XP_010940050.1 & 3 & NP_001290502.1 & 3 & XP_019707817.1 & 8 & XP_010943604.1 & 6 & XP_010905229.1 & . & XP_010924109.1 & 6 \\
\hline Oryza sativa Japonica & XP_015618768.1 & 15 & XP_015640505.1 & 14 & XP_015648250.1 & 8 & AAT94033.1 & 1 & XP_015626863.1 & 2 & XP_015628129.1 & 1 \\
\hline Ananas comosus & XP_020097704.1 & . & XP_020096323.1 & . & XP_020090296.1 & . & XP_020106556.1 & . & XP_020097093.1 & . & XP_020083542.1 & e \\
\hline Populus trichocarpa & XP_002305413.1 & 4 & XP_006380580.2 & 7 & XP_002301898.2 & 2 & XP_002325469.2 & . & XP_002305196.3 & 4 & XP_002308751.2 & 6 \\
\hline Glycine max & NP_001240062.1 & 5 & XP_003533424.1 & 9 & XP_003519474.1 & 2 & XP_003534511.1 & 9 & XP_003547995.1 & 16 & XP_003534984.1 & 9 \\
\hline Eucalyptus grandis & XP_010027708.1 & . & XP_010024490.1 & . & XP_010061229.1 & . & XP_010051591.1 & . & XP_010062252.1 & . & XP_010057769.1 & \\
\hline Nicotiana attenuata & XP_019261019.1 & . & XP_019253532.1 & 9 & XP_019234273.1 & . & XP_019245686.1 & 8 & ABQ53935.1 & . & XP_019251827.1 & 8 \\
\hline Vitis vinifera & XP_002282761.1 & 17 & XP_002277919.1 & 5 & XP_002275827.1 & 18 & NP_001304059.1 & 19 & XP_002283364.1 & 18 & NP_001267864.1 & 19 \\
\hline Morus notabilis & XP_010101212.1 & . & EXC03145.1 & . & XP_010094509.1 & . & XP_010111085.2 & . & XP_010095287.1 & . & XP_010103952.1 & \\
\hline Arabidopsis thaliana & NP_201085.1 & 5 & NP_193291.1 & 5 & NP_177775.2 & 1 & NP_197148.3 & 5 & NP_195399.1 & 4 & NP_199588.1 & 5 \\
\hline
\end{tabular}

